\title{
TEORÍA E INTERPRETACIÓN EN LA ARQUEOLOGÍA DE LA MUERTE
}

\author{
THEORY AND INTERPRETATION IN ARCHAEOLOGY OF DEATH
}

\author{
JAVIER RODRÍGUEZ-CORRAL \\ GEPN-AAT, Facultad de Geografía e Historia, Universidad de Santiago de Compostela. \\ Correo-e: javier.corral@usc.es. ORCID: https://orcid.org/0000-0002-6727-8029. \\ EDUARDO FERRER ALBELDA \\ Departamento de Prehistoria y Arqueología, Facultad de Geografía e Historia, Universidad de Sevilla. \\ Correo-e: eferrer@us.es. ORCID: https://orcid.org/0000-0001-8083-1565.
}

\begin{abstract}
Resumen: La arqueología de la muerte y la identidad es clave para comprender las sociedades pretéritas. A través de los restos de rituales funerarios, los arqueólogos estudian no solo las actitudes y sentimientos que los individuos en el pasado desarrollaron en relación a la muerte y el Más Allá, sino también su cultura, sistema social y visión del mundo. Este artículo proporciona una visión y síntesis de uno de los campos de estudio más relevantes en la investigación, centrándose especialmente en las cuestiones teóricas que han alentado las diferentes aproximaciones al tema a lo largo del tiempo.
\end{abstract}

Palabras clave: Muerte; identidad; ritual; historiografía y teoría arqueológica.

La noción de Arqueología de la muerte se introduce en la literatura arqueológica tras la publicación, con ese título, de una obra editada a inicios de los años ochenta (Chapman et al. 1981). Paradójicamente, este título terminó designando una aproximación al estudio de la muerte más preocupada en explotar sus huellas materiales -los depósitos funerarios-, como evidencia arqueológica para el estudio social de la Prehistoria, que en reflexionar sobre la misma idea de muerte y las diferentes implicaciones, conceptualizaciones y procesos que este fenómeno implica. En este sentido, la

\begin{abstract}
The archaeology of death and identity is crucial to our attempts to understand past societies. Through the remains of funerary rituals, archaeologists study not only ancient people's attitudes and feelings toward death and the afterlife but also about their culture, social system, and world view. This paper provides an overview and synthesis of one of the most revealing fields of research into the past, focusing on the theoretical issues that have encouraged the different approaches over the time.
\end{abstract}

Keywords: Death; Identity; Ritual; Historiography and Theoretical Archaoelogy.

expresión terminó sirviendo para designar un campo acotado y sistemático de estudio del registro arqueológico que se había empezado a desarrollar a principios de la década anterior en el seno de la autoproclamada Nueva Arqueología.

Sin embargo, el interés de la Arqueología por la muerte y las prácticas funerarias de las sociedades pretéritas surge desde el mismo nacimiento de la disciplina. La diferencia radica en que hasta los años setenta no se puede hablar ni de que existieran arqueólogos especializados en el estudio de la muerte, ni que hubiera un 
campo de estudio y de reflexión sobre las prácticas funerarias. De hecho, en gran medida, el registro arqueológico estaba constituido por el registro funerario, y una parte importante de los datos y materiales recuperados, utilizados para construir las interpretaciones generales histórico-culturales, provenían de estos contextos.

Cuestiones como saber qué representan las tumbas, cuál fue el sentido de las diferentes formas de tratar el cadáver, cómo se realizaron los depósitos y por quién, o cómo debemos interpretar las diferentes características de una tumba, son cuestiones complicadas de responder. Asimismo, tampoco resulta fácil señalar los motivos que se encuentran tras los diferentes modos de interrogar y utilizar arqueológicamente el registro funerario. En todo caso, al ser la Arqueología una elaboración secundaria de nuestra propia sociedad, la agenda política y cultural de los arqueólogos ha determinado los discursos y las prácticas de la disciplina. Quizás, lo que mejor exprese esto sean los diferentes modos en que se ha tratado la identidad en Arqueología, y cómo se ha usado el registro funerario en relación con esta idea.

El propósito de este trabajo es revisar el uso que de las formas materiales de la muerte ha hecho la investigación arqueológica, y analizar cómo la incorporación de diferentes conceptos y de planteamientos teóricos ha permitido desarrollar una Arqueología de la muerte más allá de la iniciada en la década de los setenta, que en gran medida suponen rehabilitar o adaptar planteamientos ya presentes en la Arqueología Histórico-cultural bajo un marco teórico renovado (véase al respecto Chapa Brunet 1991; 2006).

\section{LA APROXIMACIÓN HISTÓRICO- CULTURAL A LA MUERTE}

Hasta los años setenta del siglo XX, dos circunstancias marcaron los estudios arqueológicos de la materialidad de la muerte. En primer lugar, el papel que jugó el depósito funerario como fuente de información cerrada y estructurada en la construcción de la disciplina; y, en segundo lugar, las discusiones sobre las costumbres funerarias en el contexto de los estudios de las religiones primitivas en la Antropología.

A través del concepto de cultura arqueológica, el historicismo cultural sentó las bases de la disciplina. Dicha noción permitió superar el análisis tipológico de los artefactos individuales y centrar los esfuerzos en la reconstrucción espacial y temporal de los conjuntos objetuales. De este modo, más que una historia evolutiva del pasado basada en los restos materiales pretéritos, la
Arqueología Histórico-cultural desarrolló una metodología y una teoría sistemática de la construcción cultural. En una versión minimalista, la cultura arqueológica fue definida por G. Childe como «los diferentes tipos de restos -cerámicas, implementos, ornamentos, tumbas, lugares de habitación-, que aparecen recurrentemente juntos» (Childe 1929: v-vi). En este nuevo proyecto, el depósito funerario se erigió como la principal fuente de información para definirlas. Los conjuntos materiales se convirtieron en la expresión material, en el presente, de los pueblos o las etnias pretéritas, abriéndose, de este modo, el camino a un modo específico de abordar el estudio del pasado. Clark definió la Arqueología como «el estudio de la distribución en el pasado de rasgos culturales en el espacio y en el tiempo, y de los factores que gobiernan su distribución» (Clark 1933: 232).

La Arqueología difusionista, con su agenda centrada en la construcción de la identidad cultural de los pueblos (Jones 1997), encontró en los contextos funerarios un espacio de empatía con los individuos y las gentes del pasado en estrecha relación con su cultura material. Por ejemplo, desde esta perspectiva, en las tumbas principescas de Hallstatt de la Edad de Hiero se materializa la evidencia de los orígenes de una identidad cultural y una etnicidad céltica. Al ser considerados hallazgos cerrados (Rowe 1962), los enterramientos, en su conjunto, se consideraron marcadores materiales de los pueblos del pasado. Los diferentes tipos de enterramiento permitían distinguir diferentes periodos y culturas, y establecer la difusión y/o movimientos de estos pueblos (Montelius 1909). Fue esta concepción la que permitió a Piggott ver en las tumbas de la Edad del Bronce inicial de la Cultura de Wessex (Inglaterra) una prueba material de la migración de la aristocracia bretona a las islas británicas (Piggott 1938) $\mathrm{y}$, en términos generales, asumir que la propagación de las tumbas megalíticas se debió a la adopción, a la extensión y a la generalización de nuevas ideas religiosas (Piggott 1965: 60). De modo ilustrativo, a menudo las propias prácticas funerarias se utilizaron para definir pueblos y culturas, y para establecer sus áreas de influencia y expansión. Es el caso, por ejemplo, de las poblaciones de Europa central durante el Bronce Final: los arqueólogos recurrieron a la tradición de estos pueblos de cremar a los muertos, de depositar sus cenizas en urnas y luego enterrarlas en los campos, para englobarlos en la Cultura de Campos de Urnas.

La variabilidad espacio-temporal de las prácticas mortuorias documentadas arqueológicamente fue comprendida del mismo modo que las variaciones de 
los demás rasgos culturales de esas culturas y sirvieron como marcadores de la difusión y movimiento de los pueblos en el pasado. Recientemente, este modelo explicativo ha encontrado acomodo en la Arqueología actual (Roberts y Linden 2011), en el marco de los estudios que combinan análisis lingüísticos con análisis genéticos y arqueológicos del registro funerario (Sergent 1995; Oppenheimer 2006), para definir etnicidades, culturas, migraciones, etc.

Por otro lado, la Arqueología Histórico-cultural encontró en la Antropología el apoyo necesario para interpretar los rituales funerarios que el registro funerario permitía constatar. Desde finales del siglo XIX, a través de casos de estudio, paralelos etnográficos y la generalización de los mismos, se establecieron los vínculos entre las prácticas funerarias y las creencias que las motivaban, situando el factor principal que determinaba la naturaleza de esas prácticas en el contexto de las actitudes escatológicas y religiosas hacia la muerte y el Más Allá.

La conceptualización antropológica de la muerte, inspirada en gran medida por presupuestos psicologicistas, estableció premisas generales sobre las actitudes hacia el mundo de ultratumba. Tylor (1871), en sus consideraciones sobre el animismo, sostuvo que los individuos proyectaban, en el contexto de la muerte, la dicotomía cuerpo-alma percibida en los sueños. Esta dicotomía, según Frazer (1886), explicaría el miedo que, en muchas sociedades, los vivos tienen a los muertos y a sus fantasmas. Desde sus inicios, por tanto, la Antropología mantuvo en su discurso las ideas del miedo universal a los muertos (Freud 1967 [1913]: 73-101; Wundt 1911; Becker 1973) y de la negación común de la muerte a través de la creencia en la inmortalidad (Malinowski 1925; Lifton y Olson 1974). Estas dos creencias derivaron, antropológicamente, en una actitud ambivalente de los vivos con los fallecidos, y determinaron la idea misma de la muerte. Para estos autores, la muerte no es un simple acontecimiento biológico sino una transición ritualizada, un proceso en el que tienen lugar la transformación del cuerpo y el alma del difunto, y de su relación con los vivos (Hertz 1960). A través de rituales de separación, de tránsito liminar y de incorporación a una nueva identidad, el muerto pasa a formar parte de una comunidad post mortem (Van Gennep 2008 [1909]).

En muchas culturas, la cremación se asocia, por ejemplo, a la creencia de que el Más Allá se ubica en el cielo. El muerto podía ser cremado por el miedo exacerbado a su cuerpo. La combustión del cadáver permite que el alma se libere y pueda viajar al Otro Mundo celestial a través del ascenso del humo (James 1928). Como contraposición, la práctica de la momificación responde a una idea positiva del cadáver, al pretender preservar el cuerpo del muerto y asegurar la supervivencia personal del individuo (Malinowski 1925: 49; Dowson 1928: 135-136). Estas ideas están presentes en la imaginación arqueológica desde finales del siglo XIX. Lubbock asumió gran parte de las premisas de la tradición Tylor-Frazer (Lubbock 1882: 214). Al referirse, por ejemplo, a un túmulo funerario de la Edad del Bronce, afirmaba que «el cuidado con el que el muerto fue enterrado, y la costumbre de enterrar objetos con ellos, probablemente nos indica la existencia de una creencia en la inmortalidad del alma, y en la existencia material después de la muerte» (Lubbock 1900: 133).

Asimismo, las creencias quedan también plasmadas en la manera en que se deposita el muerto. Por ejemplo, para algunos autores el cuerpo flexionado estaría imitando la posición del feto en el útero, funcionando como un símbolo del renacimiento (Tyler 1921: 124). Otras formas de colocar el cadáver se interpretaron dando por cierta la premisa, antes señalada, del miedo que los muertos despiertan en los vivos. Frazer consideró que el origen de las lápidas y los cairns se encontraba en la colocación de piedras pesadas sobre la tumba, conforme al principio de sit tibi terra gravis (Frazer 1886: 65; véase Alfayé 2009: 191-197). Depositar el cuerpo flexionado y atado, en algunos casos, podría deberse a una estrategia para impedir al espíritu que pudiese caminar y retornar al mundo de los vivos (Wilder-Whipple 1917: 372; Tyler 1921: 124). La orientación del cadáver en la tumba, como Tylor afirmaba, también responde a diversas creencias (Tylor 1871: 508). Su ordenación hacia puntos cardinales cobra sentido a través de la analogía solar - puesta del sol-muerte y salida del sol-vida- y en relación con la creencia en otra vida tras el cese de los signos vitales. El cuerpo del difunto se dispondría en la dirección en la que debe emprender su viaje al Allende (Rose 1922: 132-133). Cuando el cuerpo se alinea con puntos terrestres, se relaciona con la idea de la reencarnación, ya que su posición indica el lugar donde el alma del individuo tiene que morar antes de volver a nacer (Rose 1922: 129).

Finalmente, la ubicación del depósito funerario respondería también a concepciones escatológicas y cosmológicas particulares. Los cuerpos, enterrados cerca o dentro de las casas, manifiestan el deseo de que regresen otra vez en forma de nacimientos de bebés dentro del propio clan, tribu o familia, o que se conviertan en espíritus protectores. El depósito en contextos acuáticos, 
como los ríos o los lagos, y subterráneos, como las cuevas, podrían responder a la creencia de que estos lugares eran la entrada al Allende (véase Ferrer et al. 2009). Otros motivos podrían estar igualmente relacionados con la separación entre el mundo de los muertos y el mundo de los vivos, y el miedo de estos a los seres espirituales. Persson sugería, por ejemplo, que los enterramientos micénicos de Dendra se ubicaron al oeste del área de habitación para evitar que los espíritus perturbaran a los vivos en su viaje al Hades (Persson 1942: 152-153).

Los contextos funerarios, sin embargo, sirvieron como fuentes arqueológicas de información para determinar rasgos culturales más que actitudes escatológicas y cosmológicas. La Arqueología Histórico-cultural estaba interesada en la definición y el reconocimiento de los pueblos y las culturas del pasado. Su modelo difusionista considera que la cultura -entendida como un cuerpo de costumbres que surge en el contexto de la vida intelectual y conceptual de la gente- varía directamente a través de la transmisión de ideas, siendo estos mecanismos los responsables de la uniformización cultural, y su ausencia, la causa del aislamiento entre comunidades. El difusionismo, como marco de interpretación, permitió establecer que la variabilidad mutua se debía a contactos entre grupos sociales que producen hibridaciones o substituciones de las formas rituales. Este marco permitió asumir varios presupuestos: (1) las prácticas funerarias permiten determinar creencias concretas; (2) los cambios y transformaciones de la práctica mortuoria debe ser atribuidos, por tanto, a cambios y transformaciones en las creencias; y (3) la causa de estos cambios se explica a través de las migraciones de pueblos y de la difusión de ideas por contacto entre culturas. Childe, por ejemplo, acuñó la noción de «religión megalítica» para designar al conjunto de creencias que se encontraban detrás de las tumbas y prácticas funerarias. A los grupos responsables de extender desde el Mediterráneo hasta Europa occidental durante el Neolítico estas creencias, los calificó de «misioneros megalíticos». En suma, la distribución de las tumbas indicaría los canales de propagación y el área de dispersión de esta religión y de un conjunto de creencias sobre la muerte (Childe 1940: 46).

No obstante, años antes Kroeber, tras estudiar el registro material de comunidades nativas de California, consideró errónea la premisa que presupone que todos los aspectos culturales de un pueblo, entre ellos las prácticas mortuorias, son de igual utilidad para la reconstrucción histórica (Kroeber 1927). Sobre la proposición histórico-cultural, la constatación de múltiples formas de ritos mortuorios entre estas comunidades debía reflejar una mezcla cultural. Sin embargo, comprobó que la homogeneidad de otras distribuciones de elementos culturales no soportaba esta afirmación. Sus observaciones le llevaron, por tanto, a descartar la idea de que las costumbres funerarias fueran un rasgo cultural específico de un grupo social y un reflejo fidedigno de un sistema de creencias compartido por todos los individuos de la comunidad. A la inversa, este autor reduce la práctica mortuoria a una cuestión de simple "moda", controlada por las actitudes emocionales de los individuos (Kroeber 1927: 314). Así, un ritual funerario debe explicarse como el modo elegido más adecuado para deshacerse del cuerpo del muerto, en un contexto concreto de miedo, ansiedad e inseguridad ontológica (Homans 1941).

Dos conclusiones se desprenden del trabajo de Kroeber. En primer lugar, las costumbres funerarias, al responder a factores emocionales e individuales $-\mathrm{y}$, por tanto, no estructurales-, no sirven de indicadores arqueológicos para establecer patrones de difusión y de movimiento de pueblos. La práctica de la cremación o de la inhumación puede haber sido adoptada en diferentes contextos de modo independiente y espontáneo. En segundo lugar, el registro funerario, al ser un producto de la afectación emocional, también dificulta el estudio de la religión y la cosmovisión de las comunidades del pasado (Fahlander 2003: 74).

\section{LA NUEVA ARQUEOLOGÍA Y EL $S A X E-$ BINFORD RESEARCH PROGRAM}

Dentro de una corriente positivista, a partir de los años setenta, Binford llevó a cabo una crítica tanto del programa general histórico-cultural imperante como del relativismo cultural de Kroeber. Para este autor (Binford 1971: 15), la variabilidad del rito mortuorio frente a la uniformidad del resto de los rasgos culturales, no impide sostener, como hace Kroeber, que las prácticas funerarias estén vinculadas a la estructura cultural. Al contrario, esta divergencia permite cuestionar la validez del presupuesto general historicista cultural -esto es, que las prácticas mortuorias varían únicamente por las creencias del grupo-, y afirmar que la naturaleza del contexto funerario está estrechamente relacionada con otros factores como la estructura social.

El planteamiento de Binford no es completamente novedoso. Desde finales del siglo XIX, algunos antropólogos (Yarrow 1880: 5) y arqueólogos (Lubbock 1882: 285-286) ya habían reconocido la influencia 
directa de las variables sociales - la edad, el sexo, el estatus o el parentesco- en el tratamiento del difunto. Por ejemplo, en los años cuarenta del siglo XX, las tumbas excavadas en Hallstatt no solo eran consideradas por los arqueólogos como una evidencia de una identidad cultural concreta, sino que también eran el reflejo de «una forma específica de organización social de la etnicidad céltica» (Olivier 1990: 110). No obstante, a finales de los años sesenta, recurriendo a ejemplos antropológicos, Ucko denunció el peligro que suponía establecer correlaciones arqueológicas entre la práctica funeraria, la estructura social y la identidad del difunto (Ucko 1969). Con todo, y a pesar de la coincidencia en el tiempo de su advertencia con los planteamientos de Binford, la teoría de este último tuvo una repercusión decisiva en el pensamiento arqueológico. La aportación de esta nueva arqueología funeraria radica en que ahora la relación entre la práctica funeraria y la estructura social es explicada y justificada en el marco de la teoría de sistemas (Flannery 1967) y de la teoría neoevolutiva (Service 1962).

Binford, con una concepción estructuralista del signo, señalaba que la relación existente entre el símbolo y el significado es arbitraria. Por tanto, que diferentes grupos compartan formas simbólicas funerarias no permite colegir que compartan las mismas ideas o significados. El sentido y función del rito mortuorio puede variar de un grupo a otro; así, por ejemplo, mientras algunos grupos incineran a sus jefes, otros incineran a los criminales (Kroeber 1927: 313). Explica este hecho en términos sistémicos: las leyes que gobiernan la existencia y distribución de un elemento en un sistema difieren cuando este elemento se integra en otros sistemas con una organización diferente. La alteración de la organización interna de un sistema cultural supone que nuevas unidades organizacionales son generadas por los participantes. Por consiguiente, para este autor, el reconocimiento por los participantes de las nuevas unidades referenciales puede provocar el acto de simbolización y la proliferación de símbolos dentro de los sistemas socio-culturales. Así, son las funciones representadas por las formas simbólicas, y no su trasferencia por difusión y contacto entre grupos diferentes, las que determinan su existencia y distribución.

La teoría de sistemas presupone una correlación entre posiciones funcionalmente diferenciadas dentro del sistema y posiciones socialmente diferenciadas, y, por tanto, asume que en todo sistema social debe haber una correlación entre ese número de posiciones sociales y el número de símbolos que designan tales unidades. De este modo, resulta inasumible la posición histórico-cultural que aísla las costumbres mortuorias de los aspectos estructurales, como las actividades de subsistencia y la organización social. Contrariamente, dos componentes determinan los fenómenos sociales simbolizados en cualquier situación de enterramiento. En primer lugar, la persona social del muerto. Binford reformula este concepto (Goodnough 1965) y lo aplica al contexto funerario para describir el conjunto de identidades sociales que el difunto mantuvo en vida y que deben ser reconocidas en el ritual funerario. En segundo lugar, se debe tener en cuenta la composición y tamaño de la unidad social que reconoce la posición social del difunto. Así considera que «las facetas de la persona social simbólicamente reconocidas en el ritual mortuorio varían dependiendo de los niveles de participación del grupo en el ritual, y de ahí variará directamente con el rango de la posición social que el difunto ocupó en vida» (Binford 1971: 24).

$\mathrm{Su}$ estudio comparativo de cuarenta sociedades no estatales le permite concluir que las formas de enterramiento se relacionaban con los elementos que determinaban la diferenciación interna de la comunidad y, por tanto, de su organización social. Los diferentes rasgos de identidad del difunto sirven como criterio para un tratamiento diferencial del muerto. Estos rasgos son, por un lado, (1) el estatus social, (2) el género, (3) el parentesco y (4) la edad. Los roles sociales que desempeña un individuo dentro de su grupo se ven reflejados en el número de representaciones simbólicas de esos roles, lo que queda expresado adecuadamente en el tratamiento del cuerpo, en la arquitectura de la tumba y en el ajuar mortuorio. Sin embargo, también observó que, en ocasiones, otros elementos como la causa o el lugar de la muerte pueden intervenir alterando las obligaciones que los miembros de la comunidad habían contraído con el difunto, derivadas de su persona social definida en vida, y por tanto variando el proceso ritual.

Binford también estableció una correlación entre la complejidad social y la complejidad del tratamiento ritual y simbólico del difunto. Como marcador de la complejidad social, utiliza las formas de subsistencia que le permiten establecer tipos sociales básicos que se corresponden con estadios de la complejidad social humana, en el marco de la teoría evolutiva: (1) las comunidades de cazadores recolectores -bandas y tribus de complejidad social mínima-y (2) las comunidades agrícolas -tribus y jefaturas-. Tras comparar los cuarenta casos de estudio, Binford concluía que en las sociedades igualitarias, como las cazadoras-recolectoras, el tratamiento diferencial es mínimo en la práctica funeraria y vendría marcado por criterios de género y 
edad; mientras que en las sociedades estratificadas -comunidades sedentarias que practican la agricultura intensiva-, el tratamiento diferencial vendría marcado por criterios de estatus y de parentesco.

En suma, la Arqueología sistémica opera un gran cambio respecto a la Arqueología difusionista. La forma y estructura de la práctica funeraria está condicionada por la naturaleza social del difunto, y por la complejidad del sistema que establece los tipos posibles de persona social. Así, el cambio en la actitud funeraria nunca puede ser explicado como una innovación ideacional, consecuencia del contacto o el movimiento de pueblos. En tanto que es un reflejo de la persona social y del sistema social, debemos analizar las fuerzas que operan en el sistema socio-cultural para poder explicar los cambios en las prácticas mortuorias.

No obstante, no es la única estrategia interpretativa que la Nueva Arqueología adopta para renovar el análisis arqueológico de los contextos funerarios. Paralelamente, Saxe (1970) introdujo una nueva metodología de análisis. En su tesis de doctorado, de la que solo se llegó a publicar un resumen en forma de artículo (Saxe 1971), se utilizaron por primera vez, y de modo sistemático, análisis estadísticos para estudiar el registro funerario. Asimismo, inició el estudio de la dimensión espacial de los enterramientos con nuevos planteamientos teóricos. Saxe sostenía que la emergencia de cementerios en la Prehistoria se debió al incremento de la competencia intracomunitaria para acceder a los recursos naturales y «la formación de grupos de descendencia agnaticia que intentaron monopolizar estos recursos a través de la descendencia lineal del difunto» (Morris 1991: 148). Su propuesta, testada con los informes etnográficos de tres sociedades, fue resumida en su Hipótesis 8: «en la medida que las comunidades tienen derecho a usar y/o controlar los recursos cruciales aunque restringidos que son logrados y/o legitimados por medio de la descendencia lineal del muerto (ej: vínculos lineales con los ancestros), tales grupos mantendrán áreas para el depósito exclusivo de sus muertos, y viceversa» (Saxe 1970: 121).

Goldstein revisó los presupuestos de Saxe a la luz de los datos etnográficos de treinta sociedades, y relacionó las prácticas funerarias con los patrones de asentamiento y de subsistencia, los sistemas hereditarios y los recursos naturales esenciales. Advirtió que, incluso en condiciones económicas y ambientales similares, las comunidades simbolizan y ritualizan aspectos de su organización de formas diferentes. De este modo, reformuló la Hipótesis 8 afirmando que no todos los grupos que controlan recursos críticos, a través de la descendencia lineal, mantendrán cementerios para sus muertos (Goldstein 1976; 1981). Aun así, Goldstein afirma que si existe un área delimitada, especializada y permanente para depositar exclusivamente los muertos de la comunidad, entonces es muy probable que esta pertenezca a un grupo que tiene derechos sobre el uso y el control de los recursos esenciales y restringidos. Con casi toda certeza, el control de los recursos está legitimado a través de la descendencia lineal de los muertos, ya sea en términos de un linaje, ya en la forma de una tradición fuertemente establecida que trasmite los recursos esenciales de padres a hijos. Cuanto más formada y organizada esté el área de depósito de los muertos, más concluyente es esta interpretación (Goldstein 1981).

Las premisas establecidas por el "programa Binford/Saxe" permitieron el desarrollo y consolidación de una Arqueología de la Muerte (Brown 1971; Chapman et al. 1981) centrada en el estudio de la organización social a través del análisis de los contextos funerarios -las tumbas, los muertos y los ajuares-. En este contexto, Tainter considera que «no existe otra categoría de información arqueológica más fiable» para estudiar la estructura social que el registro funerario (Tainter 1977: 329). Por tanto, más allá de los estudios etnográficos y etnoarqueológicos, los arqueólogos procesuales se afanaron en desarrollar una teoría arqueológica -esto es, una teoría de rango medio (Binford 1977; véase Raab y Goodyear 1984)- que les permitiese establecer correlaciones generales y estables entre las dinámicas mortuorias del pasado -la estructura de los rituales funerarios- y su registro material estático en el presente (Tainter 1975; 1978; O'Shea 1984). Así, se generalizó en el discurso arqueológico un conjunto de criterios básicos para establecer correlaciones entre la riqueza, la complejidad y la jerarquización social, centrados en la inversión de energía en la construcción de la tumba, en la obtención y fabricación de los objetos del ajuar (Renfrew 1973; Fleming 1973; Kinnes 1975; Tainter 1975), y en la tipificación formal de los contextos funerarios. Renfrew, por ejemplo, consideraba que durante el Neolítico, el trabajo y esfuerzo requerido para la construcción de los monumentos funerarios de Wessex, reflejaba la jerarquía de los individuos (Renfrew 1973). Fleming analizó la relación existente entre las cámaras funerarias y la superficie del túmulo que las cubría, en los enterramientos de la Edad del Bronce de las islas británicas (Fleming 1973: 178). Esto le permitió correlacionar los túmulos grandes con cámaras pequeñas con tumbas de individuos de alto rango. Asimismo, el ajuar sirvió como marcador de estatus. Uno de los criterios utilizados fue la distancia que había entre el lugar 
de origen del objeto y el depósito funerario del que terminó formando parte. Por ejemplo, Peebles (1971) en su estudio de Moundville considera que el exotismo de los objetos tendría un gran valor para la comunidad local y, por tanto, estos serían signo de estatus. Por su parte, el análisis del tamaño de los ajuares y del trabajo requerido para su producción permitió a Shennan, en su estudio de la necrópolis de Branc (Chequia), establecer las diferencias jerárquicas de las sociedades de la Edad del Bronce de la región (Shennan 1975).

Al asumir que las prácticas mortuorias reflejan la estructura social, el contexto funerario se convierte en una fuente que proporciona información para conocer la naturaleza de la sociedad. La "hipótesis Saxe/Goldstein" (Morris 1991), al reducir la formación de la expresión material funeraria a una variable unicausal -el control de las tierras y los recursos vitales-, resultó muy operativa para interpretar el registro arqueológico. Estas premisas condujeron al desarrollo de un interés por los aspectos visuales de los enterramientos, especialmente en relación al estudio de los monumentos megalíticos prehistóricos. De este modo, las prácticas funerarias dejaron de interesar en el contexto de los estudios de las religiones primitivas, y como argumento del movimiento de pueblos y cultura. Ahora son interpretadas en clave funcionalista y espacial (Renfrew 1976; Chapman 1981; 2003): como marcadores territoriales de sociedades segmentarias en el contexto de desequilibrio entre la sociedad y los recursos vitales para la comunidad. A partir de los años setenta los arqueólogos han interpretado que las tumbas megalíticas con gran visibilidad se situaban en las zonas liminares para definir las fronteras y adquirir derechos sobre la tierra (Madsen-Jensen 1982: 83).

\section{LA CRÍTICA POSTPROCESUAL Y LA INTERPRETACIÓN SIMBÓLICO-ESTRUCTURAL}

A finales de la década de los ochenta, una parte del ambiente arqueológico de Cambridge reaccionó contra los planteamientos sistémicos y funcionalistas de la Arqueología de la Muerte. La corriente postprocesualista de ahí surgida, al igual que la Arqueología Procesual, recurrió a la analogía etnográfica y antropológica, con el objetivo preciso, en este caso, de desacreditar la validez de las generalizaciones transculturales y las correlaciones simplistas establecidas por los arqueólogos durante la década anterior. Al contrario que el "programa Binford/Saxe", el nuevo tono postmoderno de esta Arqueología se ha traducido en un interés por la disonancia cultural (Moore 1994). El uso de la analogía postprocesual busca precisamente resaltar las diferencias entre las experiencias del pasado y experiencias del presente (Thomas 2004: 241). De modo general, se pueden distinguir dos fases en el uso de la analogía. Por un lado, a través de una Etnoarqueología contextual, diversos arqueólogos buscaron pruebas para defender que la estructura social solo puede ser inferida en el contexto de unas tradiciones culturales e históricas específicas (Parker Pearson 1982; Hodder 1982; 1984; 1987b; McGuire 1992; Shanks y Tilley 1987b: 43-44; véase una crítica en Reybrouck 2000). Por otro lado, se recurre a paralelos y modelos antropológicos (véase Gosden 1999; Garrow y Yarrow 2010), para deconstruir la metafísica moderna y renovar la imaginación arqueológica sobre la muerte y los contextos funerarios.

Parker Pearson fue uno de los primeros autores de esta nueva ola en señalar el peligro que entraña considerar las prácticas mortuorias como un reflejo de la estructura social. Comparó las costumbres funerarias de las poblaciones de Cambridge en los años setenta y en época victoriana. Estudió la edad, el sexo, la profesión, la religión, y marcadores materiales como los bienes, los tipos de ataúdes, el tratamiento del cuerpo, la monumentalización del enterramiento, etc. Parker comprobó que mientras en época victoriana las lápidas reflejaban inequívocamente el estatus social de la persona enterrada, en los cementerios del momento el enterramiento fue una cuestión subestimada por todas las clases sociales. Se constató también que el incremento de las cremaciones de 1930 a 1975 había sido del 60\%. La aplicación del programa de investigación Binford/Saxe a las prácticas funerarias de Cambridge actual trasmitía la imagen errónea de una sociedad igualitaria. De este modo, Parker Pearson (1982) mostró que las premisas no funcionan en todos los contextos.

No obstante, los primeros argumentos en contra de la Arqueología que engloba el "programa Binford/ Saxe" fueron presentados por Ucko (1969) años antes. Este arqueólogo expuso, a través de una serie de ejemplos etnográficos, la dificultad que entrañaba distinguir arqueológicamente diferentes niveles de riqueza en los enterramientos. En muchos casos, las expresiones de riqueza, colectiva e individual, pueden estar subordinadas a sanciones rituales y sociales. No son infrecuentes, por ejemplo, los contextos etnográficos en los que se constata la destrucción ritual de los objetos. Además, Ucko señaló que los artefactos que aparecen dentro de las tumbas pueden tener más funciones que la de representar el estatus del difunto (Ucko 1969: 265). Entre los 
Nankanse de Ghana, los objetos que se disponen junto al difunto son pertenencias de los vivos, y son colocados ahí para evitar que su alma quede atrapada en la sepultura. Por tanto, muchos de estos objetos poco tienen que ver con la vida del difunto: ni reflejan su persona social, ni la estructura social del grupo.

Para el postprocesualismo, la cultura material no debe entenderse como un reflejo de la sociedad sino como formas materiales socialmente activas (Hodder 1982: 141-146; Shanks y Tilley 1982; Parker-Pearson 1982). Con todo, mientras Hodder y sus discípulos están de acuerdo en que la cultura material -constituida como símbolos materiales-es un instrumento de acción social, difieren en el modo de conceptualizar y comprender esta nueva función de los artefactos. Aunque les une su crítica a la Nueva Arqueología, el programa teórico que contraponen difiere en algunos aspectos. En cierta forma, la explicación se puede encontrar en el contexto intelectual general donde se fraguó el Postprocesualismo, que podemos calificar, siguiendo a Harland (1987), como superestructuralista: un conjunto de ideas, planteamientos e intereses propios del estructuralismo, el postestructuralismo, la semiótica, el marxismo-estructural, la psicología lacaniana y los estudios culturales foucaultianos, que buscan nuevas formas de pensar que permitan romper con el pasado (véase Bapty y Yates 1990). En este contexto, los planteamientos de Hodder sobre el papel activo de la cultura material representan la concepción más liberal de este esfuerzo en Arqueología. Recurre a la idea de negociación para subrayar que los símbolos materiales no son solo «buenos para pensar» (Levi-Strauss 1962: 162), sino también «buenos para actuar» e influir a través de ellos en el mundo (Hodder 1984; 1992: 96). Los símbolos materiales y los principios estructurales son usados para formar acciones sociales y, a su vez, son reproducidos, reinterpretados y transformados como resultado de estas acciones. Por otro lado, discípulos de Hodder, adoptando posiciones afines al marxismoestructural, apelan al concepto de Ideología para comprender las prácticas funerarias (Parker Pearson 1982). Estos autores analizan cómo los símbolos materiales y los principios simbólico-estructurales implícitos en estas prácticas construyen y legitiman discursos de poder dentro de la comunidad. Desde este punto de vista, los símbolos son utilizados para legitimar los intereses particulares. En este sentido, la ideología funciona como un modo de presentar los intereses particulares como universales, y como una forma de negación y transmutación de las contradicciones sociales. Comúnmente, según afirma Hodder, diferentes ideologías coexisten en un mismo contexto, en el que existe un constante intento para subvertir la ideología dominante desde otros puntos de vista. Así, el contexto funerario es uno más de los posibles espacios para negociar los diferentes poderes y significados, y los rituales mortuorios son un tipo de prácticas sociales que los vivos utilizan para negociar, exhibir, enmascarar o transformar las relaciones sociales y de poder.

Apoyándose en los datos que obtiene sobre los enterramientos Nuba en su investigación etnoarqueológica en Sudán, Hodder revisa las premisas establecidas por Saxe, y concluye que las prácticas funerarias «refuerza(n) un ideal social que solo es una parte de lo que existe en la práctica y sobre el que existe una preocupación» (Hodder 1982a: 197-198). De este modo, Hodder niega que los enterramientos sean naturalizaciones ideológicas del orden social, y desestima la función social de los monumentos megalíticos como marcadores territoriales (Hodder 1984). En este sentido, contrariamente a lo que sostiene la Nueva Arqueología, en numerosos casos, las tumbas megalíticas se ocultan deliberadamente para que no puedan ser vistas desde los asentamientos o desde otras áreas de actividades (Tilley 1993: 79; Parker Pearson 1999: 124).

Frente a las interpretaciones funcionalistas, Hodder propone una nueva lectura en clave simbólica. Basándose en el isomorfismo entre los long barrow y las casas de la cultura Linearbankerimik, afirma que las casas de los vivos podrían estar simbólicamente representadas en las formas materiales de los enterramientos -las casas de los muertos-. En realidad, Hodder llega a la misma conclusión que autores difusionistas hicieran un siglo antes (véase Tilley 1999: 93-94); aunque en este caso, su idea lleva aparejada una explicación social y el reconocimiento explícito del papel activo de los monumentos funerarios. Sugiere que las tumbas son espacios de negociación donde «el linaje se apropia de la reproducción femenina», y en donde fue resuelta la pugna entre los derechos maternos y paternos de acceso a los recursos.

Otro aspecto que ha centrado la crítica postprocesual al "programa de investigación Binford/Saxe" ha sido su incapacidad para explicar el contenido o la lógica interna de la actividad funeraria. Para estos autores, la posición funcionalista obvia el contexto cultural de la práctica mortuoria (Hodder 1984) y no explica «por qué ciertos objetos son reiteradamente elegidos como elementos constitutivos de la tumba, la disposición especifica que adoptan, o por qué otros elementos de la cultura material son considerados inapropiados para este propósito» (Shanks y Tilley 1982: 152). El postprocesualismo encuentra la solución a este 
problema en el análisis de los principios estructurales y simbólicos de la cultura material. Desde este enfoque teórico, los significados de la cultura material emergen de las relaciones de los significantes materiales dentro de un sistema o red de significantes, relacionados a través de contrastes, opciones y diferencias. Hodder señala que la cultura material de un grupo social funciona como «un conjunto estructurado de diferencias» dentro de un texto (Hodder 1982b: 7). Recurre a la analogía textual para remarcar que el significado tiene lugar «en asociación» o «en contexto»y que, por tanto, los artefactos enmudecen cuando están «fuera de sus textos» (Hodder 1986: 122). El planteamiento no es completamente estructuralista, ya que este autor atenúa el componente transcultural de esta teoría, al integrar en su planteamiento, a través de su idea de "contexto" (Hodder 1986: 156), la noción gadameriana de horizonte hermenéutico (Gadamer 1977). Sostiene que se pueden documentar en muchas sociedades los mismos principios simbólicos diádicos -limpio/sucio, hombre/mujer, vida/muerte- y modelos o analogías a partir de las cuales las sociedades dan sentido a sus acciones -por ejemplo, un modelo que relaciona la dicotomía puro/impuro con la diferenciación sexual (Douglas 1966)-. No obstante, estos se articulan de modos y formas diversas dependiendo de cada contexto cultural (Hodder 1982a: 215).

Por ejemplo, en su estudio etnoarqueológico entre los Nuba de Sudán, Hodder analiza el uso particular que entre estos grupos se hace de oposiciones estructurales. No niega que los enterramientos expresen diferencias de género, edad o de grupo, ni que la agrupación de los enterramientos en cementerios comunales enfatice los derechos heredados por la comunidad sobre la tierra. Sin embargo, en el contexto cultural Nuba también existe una «clara relación entre la muerte, el grano y la fertilidad» (Hodder 1982a: 168). Entre los Nuba Mesakin, la decoración tiene una función apotropaica: delimita y protege de la suciedad y la polución simbólica las áreas sensibles que están destinadas a la elaboración de comida, a la moltura del grano o al aseo de personas. Principios estructurales como limpio/ sucio, masculino/femenino y vida/muerte adquieren un sentido particular cuando se estudia cómo funciona el conjunto de relaciones materiales y simbólicas de estas comunidades. En este contexto, la muerte es una amenaza porque rompe con el ciclo de la vida y pone en peligro la continuidad de la comunidad. Por tanto, requiere de la práctica ritual y del poder de los símbolos para restablecer el equilibrio. Para Hodder, la muerte de un individuo es contrarrestada, a diferentes niveles, con símbolos de fertilidad: a través del isomorfismo entre los enterramientos y los graneros, el uso de cerámicas para cubrir la entrada a las tumbas y a los graneros, el uso de cenizas durante el entierro -símbolo de fertilidad, fortaleza y continuidad-, o el recubrimiento del cuerpo del difunto con pieles de cerdo. Asimismo, la rotura de los ítems asociados con el muerto y ritos relacionados con la fertilidad del grano permiten eliminar la impureza del cadáver.

A través de una aproximación simbólico-estructural, Hodder analiza la domesticación simbólica de lo salvaje en el contexto funerario neolítico de Çatalhöyük (Turquía) (Hodder 1990). Contrapone los enterramientos masculinos y femeninos: los primeros, asociados con imágenes de animales sagrados, se localizan en el área sacra situada detrás de las viviendas; los segundos, se ubican dentro de la vivienda, junto al hogar. A esta oposición espacial, se le suma el uso de diferentes ajuares: a los hombres se les entierran con armas e instrumentos de caza, mientras a las mujeres no. Partiendo de estas asociaciones, Hodder (1990: 10) propone que en Çatalhöyük funcionó una lógica de oposiciones estructurales entre hombre/mujer, interior (detrás)/exterior (delante), muerte/vida, salvaje/doméstico. Los símbolos peligrosos -vinculados a la muerte y a lo salvajefueron domesticados dentro de la casa, al ser separados y controlados por el área femenina de la casa. Por tanto, a través de la manipulación de los símbolos materiales diádicos, la vivienda desempeñó una importante función en el proceso de domesticación.

Por su parte, Shanks y Tilley prescinden de la idea hodderiana de contexto, introduciendo la iterabilidad en el análisis estructurado de la cultura material (significantes), permitiéndoles asumir un relativismo interpretativo y la posibilidad de diferentes lecturas. Inspirados en la noción de signo que propone Derrida, consideran la cultura material como la materialización de signos metacríticos; signos cuyo significado permanece radicalmente disperso a través de una cadena abierta de significados y significantes. De este modo, la plenitud del significado de la cultura material se consigue por virtud de su relación con otros signos, y el significado del registro arqueológico no puede reducirse a los elementos que lo componen. En suma, consideran que su «análisis debe intentar descubrir que yace detrás de las presencias observables, las similitudes y diferencias que constituyen los patrones de cultura material en un contexto temporal y espacial» (Shanks y Tilley 1987b: 102-103).

La reinterpretación que estos autores hacen de las prácticas mortuorias neolíticas de las regiones de 
Wessex y las Cotswolds (Inglaterra) y de Escania (Suecia), ilustra lo dicho. Analizan los principios estructurales generados por la disposición de los restos humanos en las tumbas comunitarias (Shanks y Tilley 1982). Determinadas oposiciones -individuo/grupo, limitado/no limitado, hombre/mujer, derecha/izquierda y cultura/ naturaleza-, según estos autores, tuvieron una gran importancia para las comunidades neolíticas, evidenciándose de un modo especial en el contexto de las prácticas mortuorias. Así, la manipulación de los huesos de los muertos tuvo una función ideológica: su reagrupación en conjuntos selectivos sirvió para reafirmar lo colectivo y negar la diferencia entre los individuos. Al reordenar los restos desarticulados de acuerdo a simetrías corporales básicas tales como cuerpo/miembro, arriba/ abajo y derecha/izquierda, que creaban simetrías entre partes del cuerpo, las composiciones óseas negaban las relaciones asimétricas de las relaciones dominantes de producción. De este modo, el ritual y las prácticas funerarias en estos espacios megalíticos, lejos de reflejar la estructura social, ocultaba las desigualdades sociales a través de una estrategia ideológica que reafirmaba lo colectivo.

\section{MATERIALIDAD, FENOMENOLOGÍA Y SINESTESIA}

La tentativa de analizar la cultura material de los contextos mortuorios como un sistema estructurado de diferencias -versión estructuralista-, o como un sistema de discurso o un segundo orden de escritura -versión postestructuralista-, pronto mostró sus carencias. Como reconocieron Shanks y Tilley (1987b: 98-105) y Hodder (1989: 258; 1991), la aproximación simbólicoestructural es incapaz de dar cuenta de la historicidad y formación de esos contextos. Asimismo, al centrarse en el espacio relacional de las diferencias a nivel simbólico como fuente de significado, obviaba el papel que las propias formas materiales tienen en ese juego para generar significado y poder.

La solución la facilitó, dentro del propio postestructuralismo, la noción de dispositivo de Foucault (2000; véase Waterman 1990: 92-94), que tiene en cuenta los aspectos materiales que la idea de discurso obvia, pero sobre todo, las teorías de la práctica y de la estructuración de Giddens (1998) y Bourdieu (1977). Desde el punto de vista de estos dos últimos autores, la agency no se comprende como la habilidad de un individuo para afectar a otros, sino como la cualidad dual socialmente reproductiva de la acción. Así, existe una relación dialéctica entre la estructura-que permite y canaliza la acción- y la acción -que, a su vez, crea las estructuras- (Barrett y Fewster 2000: 27-28; Robb 2010: 498). No obstante, la agency no es solo un fenómeno social, sino que está constituida por las condiciones materiales de acción (Giddens 1979). La performatividad de los lugares también es central al concepto de habitus de Bourdieu. El habitus no lo constituyen las reglas, dentro de las cuales las comunidades viven (lógicas estructurales dentro de la cabeza de las personas), sino que es el marco que permite a un grupo la acción en el mundo (Bourdieu 1977).

Este enfoque tuvo implicaciones directas en la Arqueología de la Muerte. En la década de los noventa, los arqueólogos adoptaron una aproximación al estudio de los espacios mortuorios centrada en los vivos, al asumir el hecho obvio de que «los muertos no se entierran a sí mismos» (Parker Pearson 1993: 203-204; Tilley 1996). La constatación de que las tumbas megalíticas neolíticas eran espacios de acceso continuado de personas y, por tanto, un lugar no solo para los muertos, sino también para los vivos, reforzó esta idea. En los años ochenta, el postprocesualismo remarcaba que «los sistemas sociales no están constituidos por roles, sino por prácticas sociales recurrentes» (Parker Pearson 1982: 100). Barrett sostiene que las formas materiales tienen un papel activo en la constitución de las sociedades del pasado al proporcionar «las condiciones materiales que necesaria y activamente facilitaron ciertas estrategias de la práctica social» (Barrett 2001: 156). Esta aproximación permitió a los arqueólogos considerar la arquitectura funeraria como una tecnología material (Barrett 1994: 134), y creó las condiciones para restituir el papel de los vivos como agentes que existen en, y comprenden explícitamente, su paisaje en acción.

Lejos de reflejar las relaciones sociales de los vivos, diversos autores manifiestan que las prácticas mortuorias son «un campo de discurso» que producen activamente las relaciones sociales (Barrett 1994; Parker Pearson 1992; 1999; Thomas 1996; Edmonds 1999). La arquitecturización del espacio funerario crea espacios segmentados y ordenados que estructuran a los actores vivos que se incardinan e interactúan con los muertos. Los cadáveres y los restos óseos se interpretan ahora como símbolos materiales que funcionan como recursos estratégicos para desarrollar discursos sociales y políticos en el pasado. Desde esta perspectiva, la Arqueología de la Muerte debe de explorar las condiciones específicas materiales de los monumentos funerarios que estructuran las relaciones sociales y de identidad (Barrett 1987: 471; 1988: 31). 
El giro fenomenológico (Gosden 1994; Thomas 1996; Tilley 1994) que también tiene lugar en esos momentos permite defender posiciones similares, al señalar que las relaciones sociales no deben reducirse a un asunto únicamente entre sujetos sociales, ya que en ellas «las materialidades están siempre implicadas de diferentes formas» (Gosden 1994: 77). Esta aproximación subraya el papel del cuerpo como nexus entre el individuo y el mundo y, por tanto, su importancia en la experiencia espacial de los individuos en el contexto funerario (Thomas 1996). Así, los individuos interpretan el espacio monumental como agentes incorporados, insertos en el mundo material a través de su cuerpo. La colocación, la orientación y el movimiento en el mundo material a través del cuerpo estructuran su asunción del espacio. Thomas, por ejemplo, interpreta el sentido de los monumentos megalíticos en la necesidad de establecer un control ideológico sobre la población, y traslada, por tanto, el significado de estos espacios mortuorios a la estructura política.

Tilley, por su parte, sugiere la necesidad de adoptar una aproximación fenomenológica que pueda ayudar a los arqueólogos a acceder y comprender no solo experiencias del pasado, sino también interpretaciones de este, incluyendo los significados simbólicos adscritos a materiales particulares, a características y lugares del paisaje. Así, este autor pretende ir más allá de la aproximación simbólico-estructural, en la que la materialidad juega una importante función en la construcción simbólica de los contextos funerarios. Se trata de una visión sofisticada y más evolucionada que aquellas que ofrecen las primeras perspectivas normativas y fenomenológicas (Tilley 1994; 1999; 2004; 2008).

La debilidad del modelo diádico y de la metáfora textual $-\mathrm{y}$, por tanto, de la idea de simbolización como un proceso arbitrario-, llevó a la necesidad de explorar nuevas vías de análisis. Hodder, en su interpretación de las tumbas neolíticas como casas para los muertos abrió el camino a nuevos modelos de análisis del simbolismo (Hodder 1987a: 2-3; 1990: 149-155; véase también Yates 1990: 169; Tarlow 1999: 34-49; Rakita et al. 2005; Tarlow y Nilsson-Stuz 2013). Sin embargo es Tilley (1999), en Metaphor and Material Culture, quien asume decididamente que los significantes materiales son diferentes a los significantes lingüísticos, y que a diferencia de estos, los símbolos tipifican o representan algo por asociación o posesión de propiedades análogas. Los atríbutos físicos y los usos de la cultura material, aunque no determinan completamente el valor sígnico de las formas materiales, desempeñan un papel importante. De este modo, cobra especial importancia la relación existente entre la materialidad y el significado (Miller 2005; Ingold 2007; Boivin 2004; 2008). Por ejemplo, la tierra (y el barro) en muchas culturas es un símbolo de fertilidad, pertenencia y propiedad, y suele estar relacionado con la mujer porque «las cosas crecen en él y puede crear una cantidad de formas nuevas» (Boivin 2004; 2008: 42). Así, puede funcionar como metáfora material en contextos funerarios como una tecnología del recuerdo (Kirk 2006; Jones 2003). También se ha señalado la relación existente entre el ciclo agrícola y las concepciones de la vida y la muerte en las cosmovisiones de las comunidades del Bronce Final y de la Edad del Hierro (Bradley 2002a). Otro ejemplo lo encontramos en el valor metafórico de la piedra. A través de una analogía con la antropología de Madagascar, Parker Pearson y Ramilisonina sostienen que la durabilidad de la piedra representa la muerte, y que la fragilidad de la madera simboliza la vida. Por su dureza y resistencia al tiempo, la piedra se asocia a los cuerpos de los hombres, y se convierte en un símbolo habitual de los linajes y los ancestros. De este modo, en su deconstrucción del pasaje de Stonehenge, afirman que en los alrededores de este monumento, donde se documentan woodhenges, se crea un dominio de los ancestros y otro de los vivos, y en el medio se establece una zona liminal para los enterramientos (Parker Pearson y Ramilisonina 1998).

La importancia que cobra la materialidad a partir de estos momentos se ve reflejada en un interés por las dimensiones sinestésicas de los monumentos funerarios y los paisajes sagrados. En este contexto, Tilley (1994; 2004) centra su planteamiento en la importancia del cuerpo, a través del cual vivimos el mundo y desarrollamos nuestras experiencias de vida. Pero el cuerpo no solo es el nexus entre el individuo y el mundo en el pasado, sino que también es la conexión objetiva entre el arqueólogo y las personas que vivieron en el pasado: es el mínimo común denominador que nos permite lograr una fusión de horizontes entre el presente y el pasado (Gadamer 1977). En este sentido, su empleo de la fenomenología no se reduce a un simple esquema teórico para comprender cómo las personas se incardinan con el mundo (embodied lives), sino que funciona como una hermenéutica que permite al arqueólogo a través de su incorporación (embodiment) acceder a las experiencias de la gente del pasado.

Este autor vincula la capacidad de interpretación de los contextos mortuorios a la experimentación de estos espacios por el arqueólogo. La interpretación es el producto de la incardinación material culturalmente circunscrita con el mundo. Las comunidades del pasado y los arqueólogos ordenan el mundo y su significado a través 
de sus cuerpos. Tilley (2004: 4-5) señala seis dimensiones inherentes a la bilateralidad del cuerpo (arriba/abajo, delante/detrás, derecha/izquierda, etc.) que nos ponen en contexto y permiten que comprendamos el mundo de un modo concreto. A través del cuerpo en movimiento, estas coordenadas adquieren relevancia somática y llegan a tener una significación metafórica. Por ejemplo, en la literatura etnográfica (véase Hertz 1960), Tilley (2004: 9) afirma que es habitual encontrar «la asociación de la derecha con el este, la vida y la salida del sol, el dominio de lo sagrado, y la izquierda con occidente, la muerte, la puesta del sol, el dominio de lo profano, la derecha con el bien, y la izquierda con el mal».

La perspectiva fenomenológica que propone Tilley permite centrar el estudio de los espacios funerarios en el sentido cosmológico y escatológico que crean las formas materiales y simbólicas de los monumentos funerarios. Por ejemplo, las entradas de monumentos funerarios irlandeses como Newgrange, Dowth y Knowth están alineadas hacia los equinoccios y los solsticios. Apoyándose en información arqueológica y geoastronómica de estos templos, Tilley sugiere que el movimiento alrededor de Knowth tuvo lugar en la dirección de las agujas del reloj, como el sol. En contraposición a este movimiento circular y repetitivo que expresa un viaje sin principio ni fin, dentro del monumento el movimiento es lineal, finito y direccional: «uno alcanza a destino, un punto final en el viaje». Por tanto, según este autor, «los corredores y las cámaras funerarias objetivan un viaje desde la vida a la muerte y al Más Allá en el que la experiencia es transformada a través afectos corporales. Por contraste, el movimiento alrededor del monumento es un viaje para la vida y las ceremonias asociadas con la vida» (Tilley 2008: 176). Al conseguir re-experimentar los movimientos lógicos de esas comunidades en relación a la arquitectura y el paisaje, Tilley adquiere una experiencia del lugar que le permite establecer una oposición entre el movimiento dentro del templo y el movimiento fuera de este. En el interior del templo «el movimiento es lineal, finito y direccional». Esto supone que al moverse a través de él, uno alcanza un destino, un punto final en el viaje. Por otro lado, el movimiento alrededor del contorno es una expresión de la ausencia de fin: «un viaje que no tiene inicio ni final». Dada la asociación entre los templos y los muertos, Tilley sugiere que los corredores y las cámaras objetivan un viaje desde la vida a la muerte, al Más Allá, en el que la experiencia es transformada a través de sus efectos corporales. Por contraste, el movimiento alrededor del contorno es «un viaje para la vida y las ceremonias asociadas con la vida» (Tilley 2008: 176).
Parte de las aproximaciones fenomenológicas ha centrado su atención en la sinestesia y la intersensorialidad que producen la actividad funeraria y la arquitectura mortuoria (Tilley 2008: 41-44; Howes 2006: 164-169). La construcción y el uso de las tumbas crean lugares de especial relevancia y concentración de significados. Ingold, en su reflexión sobre la temporalidad del paisaje, llevó a cabo una crítica de la dicotomía existente entre la visión naturalista del paisaje -como contexto natural a priori sobre el que se desenvuelve la actividad humana- y la visión culturalista que sostiene que cualquier paisaje es un orden simbólico y cognitivo. Ingold explora una tercera vía, en la que tiene en cuenta dos cuestiones: (1) la vida humana es un proceso que implica el paso del tiempo; y (2) el transcurso de la vida humana es también un proceso de formación de los paisajes en los que la gente vive. Con una visión heideggeriana, Ingold (1993; 1992: 51) afirma que construir es habitar. En esta línea, Bradley (1993: 21) ha señalado que los monumentos megalíticos transformaron la experiencia del tiempo y del lugar a través de las transformaciones que impusieron en el paisaje. Asimismo, las experiencias resultantes de espacios cerrados como las casas y las tumbas permitieron nuevas estrategias sociales que, para algunos autores (Wilson 1988), han tenido tanta incidencia en las comunidades neolíticas como el desarrollo de la propia agricultura.

Las construcciones y los paisajes numinosos y funerarios no son únicamente sentidos visualmente, sino experimentados a través de todos los sentidos. Mientras que el ocularcentrismo occidental (Jay 2003a; 2003b; Witmore 2006) ha tendido a considerar el paisaje como algo visual, para Ingold, en los paisajes de actividad humana (taskscape), los demás sentidos también intervienen de un modo decisivo (Ingold 2005: 520). Los modelos fenomenológicos y sinestésicos, complementando a los modelos de estructuración, han permitido que el análisis arqueológico incida en las prácticas sociales recursivas, como un modo de crear lugares con significado a través de las visitas repetidas, la celebración de eventos, de ceremonias u otras actividades. Esto ha permitido que la imaginación arqueológica preste especial atención a la relación entre la profundidad temporal, los ancestros y la creación de mitologías e historias no escritas (Rowlands y Tilley 2006; Gosden y Lock 1998; Lock 2009: 180; para una crítica de esta idea véase Whitley 2002).

El estudio de las experiencias relacionadas con la luz y la oscuridad y las sensaciones térmicas, humídicas, olfativas o acústicas, que crean experiencias y alteran el estado de las personas, ha sido llevado a cabo por diversos autores (Bradley 1989; Dronfield 1996; Watson 
y Keating 1999; 2000; Watson 2001; 2006; Oestigaard 2005; Cochrane 2005; 2006; 2007; Tilley 2007; 2008; Bradley 2009; Dowd y Hensey 2016). Rituales como la cremación condensan un conjunto de efectos sensoriales (sonidos, olores, efectos visuales) que pueden ser manipulados. Por ejemplo, Oestigaard (2005) afirma que diferentes tipos de maderas y otros materiales fueron usados para la combustión con el fin de producir y controlar diferentes fragancias. Watson y Keating han estudiado las relaciones entre las cámaras y los corredores de las tumbas megalíticas como las de Maes Howe (Mainland, Orcadas), donde el sonido de la cámara es expulsado por el estrecho corredor, funcionando así como caja de resonancia (Watson y Keating 1999). Por otro lado, Tilley (2007) ha señalado que dentro de los monumentos megalíticos irlandeses, la muerte y la oscuridad se asocian de un determinado modo, creando así un espacio performativo que marca un viaje desde la luz a la oscuridad, desde la vida a la muerte.

Asimismo, se ha recurrido a este modelo sinestésico para interpretar, más allá de la aproximación iconográfica, las imágenes grabadas en el interior de las tumbas. Mientras que en el pensamiento moderno el acto de grabar una imagen está subordinado al producto final, en muchas sociedades no occidentales el orden se invierte, al centrar el valor de la imagen en el propio acto performativo (Ingold 1993). Tilley (2007: 132), por ejemplo, ha planteado que el mismo acto de grabar sobre las piedras estaría dándoles vida y poder. Por su parte, para otros autores, la superposición de motivos abstractos en el interior de algunas cámaras funerarias - circunstancia que ha servido para intentar establecer fases de un arte megalítico- podría estar indicando en algún caso «procesos más dinámicos en los que las imágenes estaban en constante flujo» (Bradley 2009: 120). Por ejemplo, Dronfield (1995: 263; véase también Bradley 1989; 2009: 68-70; Tilley 2008: 169-170) sostiene que las formas materiales de las tumbas megalíticas generaron las condiciones ideales de privación sensorial para crear las imágenes entópticas, llamadas fosfenos, de igual forma que se ha planteado para el arte paleolítico del interior de las cuevas (Lewis-Williams y Dowson 1993; Lewis-Williams y Pierce 2005).

\section{BIOGRAFÍAS Y TEMPORALIDADES DE LOS MONUMENTOS FUNERARIOS}

No obstante, los monumentos funerarios no se pueden entender como formas materiales que sostienen un significado, o formas unívocas de experimentar el espacio, vinculadas a la planificación de su construcción. Abandonar esta metafísica de la producción permite al postprocesualismo dejar de ver estas formas materiales como estables e inmutables y empezar a prestar atención a las biografías culturales de estos espacios funerarios. Bajo esta perspectiva (Koppytoff 1986; Gosden y Marshall 1999), los monumentos no se deben comprender como hitos en una línea temporal -esto es, reflejo de un tiempo- sino como formas materiales que filtran diferentes temporalidades y concentran gran cantidad de significados y experiencias (Holtorf 1996; 1998; Whittke 1997; Bradley 1998; Bender 1998).

Según Holtorf (2008), no debemos buscar a los monumentos megalíticos una ubicación concreta en el pasado para que cobren (un) sentido, sino preocuparnos por cómo estos han sido recibidos y dotados de significado a lo largo de su vida, en los diferentes contextos que les ha tocado vivir. No se trata únicamente de reconocer la imagen fragmentada de los paisajes funerarios fosilizados de diferentes periodos. Para Ingold (2005: 520) «el paisaje es la forma más sólida en que la historia puede declararse». Desde esta perspectiva, por ejemplo, Stonehenge, más que una colección de paisajes, es un proceso histórico con múltiples temporalidades que tiene diferentes resonancias en el presente actual. Lucas (2005: 42-43) señala que si se traslada la misma aproximación a los lugares y paisajes del pasado, esto nos permitirá comprender cómo las comunidades pretéritas experimentaron su pasado y su tiempo. Fue Bradley (2002b) quien señaló la necesidad de estudiar cómo las comunidades prehistóricas comprendieron su pasado a través de estos monumentos funerarios.

El reconocimiento de la naturaleza multitemporal del registro arqueológico sugiere que los esquemas arqueológicos para pensar la muerte deben ser modificados. En esta línea, Olivier $(1999 ; 2001)$ ha criticado la noción de hallazgo cerrado, clave de la cronotipología tradicional, usada para interpretar el registro funerario. Con esta noción, se asume que los diversos objetos comúnmente llamados ajuar fueron depositados simultáneamente en la tumba y que, por tanto, el registro arqueológico de estos ajuares suministra una imagen sincrónica de un momento en la historia de las entidades culturales estudiadas por los arqueólogos.

Los objetos documentados en el interior de la tumba del siglo VI a.C. de Hochdorf (Alemania) ilustran la naturaleza multitemporal del ajuar. Los objetos procedían de lugares y de momentos diversos, y su colocación en la cámara funeraria se realizó en diferentes instantes de un proceso que se prolongó en el tiempo. Los objetos de Hochdorf evocan conexiones con diferentes lugares: 
mientras algunos artefactos eran de producción local, el origen de otros era alógeno, remitiendo a un mundo de relaciones con gentes y prácticas de otras regiones. Bradley (2009: 232) cree que estos objetos podrían representar el «mapa de las conexiones políticas del difunto». Con todo, Olivier (1999: 126-129) traza tres temporalidades que intervienen en la constitución de este teatro funerario. En primer lugar, aquellos objetos que acompañaron al difunto a lo largo de su vida; algunos de estos artefactos tenían una dilatada biografía, a tenor del desgaste y de los arreglos que sufrieron. Entre esta categoría de objetos se encuentran ítems cuyo origen es anterior a la vida del difunto, y que debieron ser adquiridos por herencia u otro sistema de circulación de bienes. En segundo lugar, aquellos objetos que fueron introducidos en la tumba y transformados durante un período que transcurre entre su muerte y el depósito del cuerpo en el interior de la cámara. Varias de las posesiones personales como las botas, los puñales o los cuernos de beber fueron recubiertos de oro en un proceso que se realizó en el interior de la propia tumba. $\mathrm{Y}$ en tercer lugar, los objetos introducidos y manipulados en el mismo contexto ritual de depósito del cadáver, como las ofrendas de comida y bebida (miel y agua mezclada). Esta secuencia habría ocurrido durante un lapso de tiempo que se puede dividir en tres tiempos del ritual: el momento previo al depósito durante varias semanas, los rituales de comensalidad que tuvieron lugar antes de ser sellada la tumba-que pudieron prolongarse desde horas a semanas-, y el periodo de construcción del túmulo que se dilató cinco años.

La noción de presente multitemporal hace hincapié en la complejidad temporal de los espacios funerarios (Olivier 1999: 122). Esto permite poner de relieve cómo, en un contexto mortuorio, los niveles de información se entretejen y los materiales de diferentes orígenes incorporados en distintos momentos se amalgaman. Así, los objetos cambian dramáticamente de significados a lo largo de su vida, acumulando, transformando, olvidando o creando usos y significados.

El concepto de biografía cultural abre un campo de investigación de los palimpsest effects (Bailey 2007). El distanciamiento en el espacio y el tiempo del contexto en donde (y para el que) fueron creadas las formas materiales y los objetos hace que sus significados puedan llegar a ser parciales, contradictorios y diferenciados, lo que no significa que estos objetos lleguen a ser indeseables, pierdan valor y queden sin uso. En su lugar, la distancia espacial y temporal puede suponer que aúnen nuevas asociaciones en sus nuevos contextos culturales y sean resignificados, pasando a ser elementos activos de nuevas identidades sociales y culturales (Appadurai 1986: 56). Como explica Edmonds (1999: 134), los monumentos funerarios pudieron reforzar ideas o posiciones que nada tienen que ver con aquellas asociadas a su construcción, e incluso en ocasiones supusieron espacios de competición y negociación de diferentes concepciones en un mismo momento del orden de las cosas.

Un ejemplo de la resignificación de la cultura material de los objetos lo encontramos en el estudio de Eckardt y Williams (2003) sobre los objetos romanos en tumbas medievales. Estos autores sostienen que los objetos depositados en contextos mortuorios anglosajones no se pueden considerar objetos heredados, como se sostiene habitualmente $\mathrm{y}$, por tanto, como indicadores de etnicidad (véase Hamerow 1994). De ser así, cabría esperar que en las tumbas sajonas del siglo $\mathrm{V}$ aparecieran mayor número de objetos romanos del siglo IV que de momentos anteriores a esta fecha, y sin embargo, esto no ocurre. Pocos ítems romanos parecen haber continuado en circulación en época sajona. La mayoría fueron redescubiertos casualmente durante la actividad cotidiana de estas comunidades o en excavaciones deliberadas de tumbas romanas, lo que explica que aparezcan reutilizadas en las tumbas medievales vasijas romanas perfectamente conservadas. Eckardt y Williams concluyen que estos objetos «carecen de una biografía conocida, y no tienen otra historia que la creada por el contexto propio de su descubrimiento». De este modo, detrás de la recuperación de estos objetos de tumbas romanas podrían encontrarse su propia naturaleza funeraria que permitiría a estos objetos «desempeñar un papel en la transformación de la identidad y la memoria del difunto». Su capacidad para participar en la construcción de las memorias sociales de estas comunidades y de su visión del pasado «derivó del mismo hecho de que los artefactos romanos fueron objetos sin pasado» (Eckardt y Williams 2003: 165).

\section{MATERIAL AGENCY: METÁFORA MATERIAL Y OBJETOS BIOGRÁFICOS}

El tratamiento de la cultura material en relación a la metáfora por parte de Tilley (1999) coincide en el tiempo con la introducción en el pensamiento arqueológico (Preucel et al. 2001; Knappett 2005; Preucel 2006) de la teoría semiótica de Pierce (1931-1935, 1958; véase Preucel 2006: 44-66) y la antropología del arte de Gell (1998), utilizada por los arqueólogos como una teoría general de la cultura material. Hodder, en un intento 
de superar el modelo simbólico-estructural, reconoce que «el mundo material parece incidir en las categorías conceptuales» (Hodder 1989: 257). Sintomáticamente, cita los signos indiciales e icónicos de Pierce como ejemplo de signos motivados. A partir de la correspondencia que se establece entre el signo y el objeto, Pierce distingue tres tipos: los iconos, los índices y los símbolos. Como símbolo, la relación que se establece con el objeto es arbitraria. Sin embargo, como hemos tenido ocasión de ver, como iconos la dependencia se basa en propiedades compartidas -aquí se incluiría la metáfora-; y como índice, se crea un vínculo directo, en tanto que el signo es afectado y modificado por el objeto que representa. El significado de la cultura material, al funcionar como índice e icono, parece violar el principio de arbitrariedad del lenguaje de Suassure. Para Pierce, sin embargo, estos modos de relación entre el signo y el objeto no son excluyentes y el significado puede resultar de su combinación.

El énfasis en la naturaleza indicial de la relación objeto-signo ha permitido a Gell plantear dos nociones: la material agency y el objeto distribuido (Gell 1998). La noción de material agency ha sido ampliamente adoptada en la literatura arqueológica (Gosden 2001; O1sen 2003; Meskell 2004; Osborne y Tanner 2007; Watts 2008; Knappett et al. 2008; Robb 2010). Para Gell, los objetos de arte actúan como agentes en los procesos sociales, ya que la entidad a la que remiten o la acción humana responsable se distribuyen a través de ellos.

En primer lugar, la idea de material agency permite reintroducir en la imaginación arqueológica modos de pensar las cosas bajo parámetros teóricos renovados que habían sido desestimados por la Arqueología científica, presentes en la Antropología desde el siglo XIX. Estamos acostumbrados a que en la esfera religiosa o mágica existan objetos con agency. Considerar los objetos y los animales como entes psicopompos y apotropaicos no es nada nuevo. La Antropología desde el siglo XIX ha recurrido a estas nociones para interpretar la cultura material, y en nuestra vida cotidiana convivimos con actitudes de este tipo. En el primer caso, el objeto tiene capacidad para proteger, y el segundo caso es capaz de ayudar al alma en su viaje al Más Allá (Alfayé 2011: 195-227). Los objetos y las formas materiales de los contextos mortuorios suelen tener una función al margen de la simple tarea de representar un significado simbólico.

Entre las tribus y las castas de la India, los motivos laberintiformes que las personas se tatuaban en el cuerpo, si se conservaban post-mortem, ayudaban al alma a encontrar el camino a la tierra de los muertos
(Gell 1998: 90). Volviendo al ejemplo de Ucko (1969) antes señalado, los Nankanse colocan dentro de las tumbas objetos que pertenecen a personas vivas porque consideran que estos tienen agency, y sirven para asegurar que el alma del difunto no quede atrapada en la tumba y pueda emprender su tránsito al Más Allá. En muchas sociedades, por ejemplo, se sacrifican animales con la idea de que «sus espíritus puedan servir como guías al difunto hacia el otro mundo» (Eliade 1960; Williams 2001). Como acabamos de ver, Eckardt y Williams (2003), en esta misma línea, interpretan que los objetos romanos en tumbas medievales no representan etnicidad, sino que desempeñan un papel activo en la transformación de la identidad y la memoria del difunto. En este caso, el poder de estos objetos podría estar en su origen funerario. En todos los casos, se resalta la capacidad de acción de los objetos frente a la de representación. Una imagen, objeto o animal, por tanto, no es sólo un símbolo de riqueza material o de etnicidad, sino un agente no humano esencial para la propia transformación del muerto en términos sociales, cosmológicos y ontológicos.

Se ha prestado especial atención también a la agency de las imágenes en contextos funerarios. Gell ha subrayado la función apotropaica, y como metáfora de la transformación, de la decoración y los diseños geométricos -grecas, laberintos, espirales- en las zonas liminares. Gell le da este sentido a la espiral, que en realidad interpreta como un laberinto, situada en la entrada del corredor de Newgrange (Gell 1998: 86-87). Este tipo de decoración geométrica, de hecho, funciona en otros espacios más allá del funerario, como puede ser el doméstico (Boivin 2008: 54-55). En necrópolis de la Edad del Bronce de Italia central encontramos un ejemplo en el que se hibridan estas dos esferas. Se han documentado urnas cerámicas en forma de casa que en su interior contienen los restos cremados del difunto y, en muchos casos, las puertas están decoradas con motivos complejos abstractos (Bradley 2009: 36). Las tumbas de corredor como Gavrinis y Newgrange están decoradas con motivos de este tipo. Tilley (2007: 132) afirma que las condiciones de visibilidad de las imágenes de muchas tumbas megalíticas nos indican que estos grabados no están pensados para ser vistos por los vivos, concluyendo que pertenecen principalmente a la esfera de los muertos, que pueden verlos y experimentarlos desde dentro de la tumba. Los muertos fueron así enterrados en el contexto de las piedras decoradas cuyo poder mágico sirvió para controlarlos.

El modo en que la social agency puede ser investida en los objetos o formas materiales, o cómo puede esta 
emanar de las cosas, es muy diverso. Entre los mecanismos que pueden actuar se encuentran la objetivización, la personificación (animación), la mímesis, etc. La idea antropológica de personificación asume que los objetos materiales pueden adoptar algunas características de las personas. Los objetos evocan prácticas humanas y son, por este motivo, entidades activas en las redes sociales, lo que hace que el objeto y el sujeto estén íntimamente relacionados. De este modo, la misma forma antropomorfa o la introducción de algún elemento de una persona podrían activar el objeto. Tilley sostiene que decorar las piedras de la cámara y el corredor de la tumba anima y despierta sus poderes inherentes:

[...] grabar una piedra fue vestir su piel, crear una nueva identidad personal para ella, una que fuese frecuentemente relacionada a con su identidad preexistente inalterada [...] entonces podemos prever que las grandes líneas de piedras que flanquean el corredor, y esas que rodean la cámara, son personas de pie enfrentadas unas a otras, como filas de personas decoradas. Los ortostatos pueden comprenderse como un modo de objetivar las identidades de los responsables de grabar sus superficies (Tilley 2008: 174).

Otra de las formas por las cuales la materialidad permite que los objetos constituyan sistemas de acción es la facultad mimética. La mímesis implica la producción real de artefactos (índices), cuya propiedad relevante es el prototipo, vía su semejanza con el original. Las técnicas miméticas y mnemotécnicas hacen que las formas materiales y los objetos parezcan tener intencionalidad al traer a primer plano asociaciones que son significativas para las personas afectadas por su materialidad. Tilley (1996: 208), por ejemplo, sostiene que los dólmenes de portal de Bodmin Moor, en Gran Bretaña, imitan los tors graníticos que salpican el paisaje del entorno. Interpretaciones análogas se han realizado partiendo de las similitudes observadas entre tumbas megalíticas del suroeste de Inglaterra y los afloramientos graníticos del entorno (Bradley 2000; Tilley y Bennett 2001; véase también Jones 2005a). Por su parte, Scarre encuentra rasgos compartidos entre los túmulos de tumbas de corredor bretones y las formas del paisaje circundante (Scarre 2000). El sentido y significado de las tumbas megalíticas, para este autor, está relacionado estrechamente con las cualidades físicas y simbólicas de los ortostatos y con el carácter sagrado de los afloramientos graníticos o de las rocas esparcidas por el paisaje de las que fueron extraídas. Para Scarre, en el proceso de transición hacia una sociedad agrícola en la fachada atlántica europea, estas relaciones materiales y metafóricas pudieron establecer un vínculo «directo entre las viejas formas de entender un paisaje animista o numinoso y los nuevos modos de comprender los paisajes culturalmente construidos» (Scarre 2008: 211; 2004; 2009).

En la misma línea que los autores anteriores, Lillios (2008), cuando analiza las placas decoradas de las tumbas del Neolítico final del suroeste peninsular (3500-2000 a.C.), interpretadas tradicionalmente como representaciones de divinidades (Gimbutas 1974), indaga sobre las propiedades materiales y metafóricas que posibilitaron que las placas tuvieran por sí solas agency. Un grupo importante de estas placas muestran un isomorfismo con las hachas que fueron potentes metáforas visuales para estas comunidades agrícolas de la Prehistoria Reciente en toda Europa y un instrumento esencial en la construcción de la personalidad social y cultural (Edmonds 1995). Al remitir a través de su materialidad al hacha, evocan el poder de transformar el bosque, cultivar la tierra, matar y ejercer la violencia (la muerte) (Lillios 2008: 117-118). Bajo esta óptica, las cosas no son contenedores neutros que se pueden llenar de significados; más bien sus cualidades intrínsecas, que se distribuyen en ellas, condicionan su sentido.

La Arqueología encuentra en la aproximación gelliana de la tecnología del encantamiento (Gell 1992), el marco idóneo para analizar el proceso que vincula a las personas y los objetos a través de la superficie decorada. Para Gell «la decoración es esencial en la funcionalidad psicológica de los artefactos» (Gell 1998: 74). Expresado de otro modo: la decoración, aunque no crea la función del objeto, sí determina la manera de comprender su función; por tanto, la decoración es intrínsecamente funcional. No se trata de saber qué significado se esconde tras un objeto o tras una escena material, sino analizar la complejidad visual de las cosas (Küchler y Were 2005; Küchler y Miller 2005) e indagar qué efecto tiene su superficie en el observador (Gell 1998: 83). Esto supone prestar atención a los aspectos constitutivos de las representaciones: los efectos que crean las características propias de los objetos (brillo, color, dureza, textura), y la capacidad de los objetos de trascender los esquemas técnicos del observador y, así, conseguir influir en él.

De este modo, el concepto permite a los arqueólogos analizar cómo diversos objetos materiales logran agency a través de efectos estéticos particulares (Gosden 2001; Jones 2002; 2005b; 2006; Wells 2008; Jones y MacGregor 2002; Buchli 2002; Boric 2002; 2003; Meskell 2004; 2005; Williams 2006; Ingold 2007; Lillios 2008; Boivin 2008; Bradley 2009). Se abre así 
un camino para el estudio de la cultura visual de la muerte de las comunidades pretéritas más allá del puramente iconográfico, basándose en la idea de que la cultura material no requiere un proceso de decodificación -situándolas dentro de un contexto mitológico y religioso- para tener poder y significado (Gell 1998; Pinney 2006). Strathern (1990), por ejemplo, considera que el poder de las imágenes no requiere más contextualización que el propio contexto de la experiencia.

Lillios (2008: 121-122) ha analizado las placas oculadas del Suroeste peninsular como una tecnología del encantamiento. Está de acuerdo con la interpretación de Gimbutas de que algunas de las placas pudieron representar lechuzas -símbolos de regeneración y muerte-. Sin embargo, no está interesada en estos objetos como un sistema de comunicación sino como objetos performativos. Su preocupación se centra en cómo trabajan estos objetos y qué papel desempeña su forma y su materialidad en la capacidad que tienen para actuar e influir. Los ojos y líneas radiantes profundamente grabadas en la piedra funcionan como mind traps (1998: 71-72), es decir, funcionarían como mecanismos que atraen o atrapan al observador, incardinándose en un tipo de oscilación ocular o de relación ocular intersubjetiva, en la que el observador mira a la placa al mismo tiempo que esta lo mira a él. Así, la interocularidad entre el observador y la placa también podría funcionar como un medio de creación de intersubjetividades multitemporales. Cuando se mira a esos objetos, particularmente si uno es arqueólogo, puede reconocer que estas placas miraron a las gentes del pasado como nos miran ahora a nosotros en el presente (Lillios 2008: 123).

Lillios (2008: 50), al igual que otros autores (Osborne et al. 2007; Wells 2008; Bradley 2009), reconocen la utilidad de esta aproximación, más aún en contextos prehistóricos, aunque reconocen sus limitaciones si no se tienen en cuenta los aspectos simbólicos e iconográficos. Con todo, permite resaltar aspectos que el propio análisis iconográfico ha obviado: el ritual funerario no es simplemente un sistema de comunicación simbólica, sino que está formado por actos, prácticas y formas materiales dentro de un sistema de acción en el que las formas materiales y la decoración crean estructuras de sentimiento y emoción a través de la experiencia. A través de los sentidos, percibimos las cualidades formales de los objetos que nos afectan de un modo que resulta difícil de plasmar con palabras. Algunos autores se han interesado en cómo las emociones son escenificadas (Gosden 2004: 36; Hofmann et al. 2011: 191-195; Williams 2006; 2011). Por ejemplo, Williams (2006: 135-141) interpreta las tumbas de Sutton Hoo
(Suffolk, Inglaterra), no tanto como un espacio que encierra un significado simbólico profundo, sino como una tecnología del encantamiento. Cuando se ilumina la cámara funeraria, los colores de los textiles, el brillo de los objetos áureos, la iconografía de zoomorfos, las sensaciones táctiles, y los sonidos y aromas crean un espacio coreografiado, que para el observador representaría una escena animada. La evidencia arqueológica bajo una perspectiva gelliana permite a Williams considerar que la tumba pudo ser utilizada como una composición mnemotécnica construida a través de la percepción y la experiencia de su materialidad.

La introducción de la idea de material agency en la Arqueología de la Muerte permite comprender los objetos y las imágenes como sistemas de acción social, y abre una vía para estudiar el uso que los humanos hacen de los objetos para distribuir parte de su personalidad en ellos (en relación al proceso de objetivización de la personalidad véase Munn 1986; Mauss 1990; Strathern 1988; Miller 1987; Gell 1998: 18-19; Tilley 2006). En este contexto, ha surgido un especial interés por el papel que las emociones juegan en las relaciones entre las personas y las cosas. Así, Wells (2008: 55) afirma que si nuestra reacción es suficientemente poderosa, entonces podemos responder a lo que vemos, y esta respuesta puede ser emocional, puede ayudarnos a tomar una decisión o a actuar de un modo determinado. Si esto ocurre, podemos decir entonces que la imagen o el objeto tienen agency.

Sólo recientemente los arqueólogos han empezado a considerar las experiencias somáticas de los vivos en el contexto de las prácticas mortuorias (Meskell 1996). Gosden (2004) y Boivin (2008) han señalado la necesidad de atender a los vínculos entre el cuerpo, los objetos y las emociones, y cómo estas pueden ser canalizadas y evocadas por las cosas. Hallam y Hockey (2001: 13) prestan atención a cómo la experiencia emocional ayuda a crear memoria. Así, se interesan en cómo los objetos asociados con el muerto están imbuidos de resonancia emocional y adquieren una densidad de significados que induce, condensa y canaliza miedo, ansiedad, tristeza, etc. La emoción también es esencial en la función psicológica de los artefactos, pero su fuente no sólo se halla en el valor estético del objeto, sino también en su valor biográfico.

En el transcurso de su trabajo de campo en la isla de Sumba (Indonesia), Hoskins comprobó que los objetos eran usados entre los Kodi para aludir y reflejar momentos claves de la vida de una persona: «Lo que descubrí, para mi sorpresa, fue que no podría reunir las historias de los objetos y las historias de vida de las personas 
de un modo separado. La gente y las cosas que valoraban estaban tan completamente entretejidas que no podían desenmarañarse» (Hoskins 1998: 4). Esta antropóloga definió entonces la categoría conceptual de objetos biográficos que trae a primer plano la inalienabilidad y capacidad de los objetos de acumular significados (Weiner 1992; Appadurai 1986; Kopytoff 1986). Para Hoskins este tipo de objetos proveen un importante modo de traer el pasado al presente, y son una de las fuentes a partir de las cuales las historias y las identidades de las personas son creadas. Al mismo tiempo, las trayectorias (temporales, espaciales, contextuales, etc.) de los artefactos pueden ser independientes de individuos específicos, interviniendo en sus experiencias solo brevemente antes de que continúen tocando otras vidas. Cualquier colección de objetos materiales, como los estudiados por los arqueólogos, puede ser, temporalmente, una acumulación de artefactos que se relacionan de forma diferente con el paso del tiempo.

Hoskins (1989) analizó la historia de la cabeza cortada de un noble de Rara, llamado Rato Malo, que cayó en una emboscada de cazadores de cabezas Kodi a finales del siglo XIX. Su hijo más joven fue capturado y vendido como esclavo. Con el tiempo llegó a trabajar para la primera misión católica en la isla. Aprendió a leer y a escribir y fue bautizado como Yosep. Años después regresó a su tierra para trabajar en la administración colonial. Con el poder adquirido en el ejercicio de esta tarea negoció el retorno del cráneo de su padre como parte de la contraprestación de la dote. El cráneo fue tratado ritualmente, primero como un valor de intercambio femenino, luego fue vestido con ropa masculina, reunido con los huesos del cuerpo, y vuelto a enterrar como persona (Hoskins 1989). Las transformaciones de ese $o b$ jeto biográfico muestran cómo la línea entre las personas y las cosas puede ser difusa y variable, y, también, cómo otros objetos inanimados (ropa, ornamentos, etc.) pueden ser dotados con cualidades de personas. La historia de la cabeza de Rato Malo es un llamativo ejemplo de cómo lo que había sido una vez parte de un cuerpo humano llegó a ser tratado como un valioso objeto de intercambio, para ser luego ritualmente transformado en parte de una persona otra vez. Su significado para sus descendientes fue fácil de comprender, y su retorno fue requerido para restaurar el honor y fertilidad de su familia. Pero al sostener que otras cosas - no solo estas que fueron una vez parte de los cuerpos humanos- podrían también ser objetos biográficos, señala Hoskins (1998: 7), se debe «transgredir las fronteras útiles entre personas y objetos y mostrar hasta dónde ciertas posesiones puede llegar a ser vistas como yoes subrogados».
Interpretar los elementos de un ajuar como objetos biográficos tiene una importante implicación para la Arqueología de la Muerte: los objetos están mucho más estrechamente relacionados y vinculados a los relatos vitales de la gente que a las instituciones sociales, como pretendía Binford. Un ejemplo de esto lo encontramos en el episodio del cetro de Agamenón (Ilíad. II, 100108 ), donde se narra cómo este objeto fue realizado por Zeus, pasando posteriormente por diversos propietarios como Hermes, Pélope, Atreo y Tiestes, siendo este último el que se lo regala a Agamenón. Como señala Whitley (2002: 221), «la genealogía del objeto refleja en parte la genealogía de Agamenón, y habla elocuentemente de su estatus como gran rey». Estos objetos se entretejen a través de sus biografías con las biografías de los héroes en la estructura del relato homérico. Whitley, en su estudio de las tumbas de guerrero del Bronce Final y la primera Edad del Hierro en Grecia, examina la relación entre biografías objetuales y tumbas de guerreros en el contexto arqueológico. Concluye que «las tumbas guerreras de inicios de la primera Edad del Hierro representan la convergencia y el cierre de dos tipos de narrativas: la historia personal del muerto y la biografía cultural de los objetos más antiguos y valiosos». De este modo, existe una homología entre la estructura narrativa de la Ilíada con la narrativa creada -y traída a su fin- en los funerales de los guerreros, reforzada por el fin de la biografía cultural de los objetos. Esta convergencia de los relatos personal y material permiten crear un nuevo ideal cultural: «el guerrero como héroe» (Whitley 2002: 227).

En la misma línea, Robb ha utilizado el concepto de la biografía de la muerte para analizar la variabilidad de las prácticas funerarias que se documentan en el registro arqueológico (Robb 2002; 2007; véase también Golwland 2004; Williams 2006: 97). En este sentido, las variaciones en el enterramiento se deben interpretar, según este autor, en relación al cuándo, al cómo y al porqué de la muerte de un individuo. Asimismo, recurre al concepto de biografía - frente a la noción de persona social-, para prestar especial atención a la secuencia de prácticas culturales y sociales que construyen la vida de un individuo, y defender que las biografías de estos individuos son «historias de un cuerpo particular» (Robb 2007: 288). Como síntesis, para Robb existen modos apropiados para morir para la gente con diferentes biografías, e inversamente, la manera de morir afecta a cómo la biografía particular es comprendida; el énfasis en esto último ha derivado en un interés por las muertes no normativas o anormales que requieren de prácticas rituales excepcionales (ejemplos en Shay 
1985; Johnston 1999; Taylor 2002; Hoskins 2005; Williams 2006: 99-100; Richardson 2007; Katz 2007; Murphy 2008; Reynolds 2009; Charlier 2009; Alfayé 2009; 2010; Belcastro y Ortalli 2010). Las diferentes biografías surgen a través de una historia personal en la que una relación entre el cuerpo y el conjunto de objetos que dan sentido a la personalidad de ese individuo se dan cita, de tal forma que cuando esta termina, cuerpo y objetos tendrán un modo coherente de llegar a su fin.

En suma, bajo estas aproximaciones, los diferentes elementos depositados en el interior de las tumbas son interpretados por los arqueólogos como objetos que acumulan significados y tienen agency. Al citar los prototipos a los que remiten -tiempos, acontecimientos, lugares, personas, historias, etc.-, los ítems crean escenarios de personalidad extendida, y permiten que los enterramientos funcionen como potentes lugares de creación de memoria, identidad y poder (Alcock 2002; Van Dyke-Alcock 2003; Boric 2003; 2009; 2010; Casella y Fowler 2005; Williams 1998; 2003; 2006; Insold 2007; Mills y Walker 2008; Holtorf y Williams 2006; García Sanjuán y Wheatley 2010; Lillios-Tsamis 2010). De este modo, la idea tradicional de ajuar funerario como la acumulación de la riqueza de individuos de alto rango social -que esconde tras de sí la idea de que la tumba y su ajuar son siempre un reflejo pasivo de la estructura social y la persona social del muertopierde todo el sentido para estos autores. La acumulación de objetos en la tumba puede ser explicada como fruto de la integración social que el conjunto de objetos de procedencias y tiempos diferentes permite establecer (Jones 2002: 169).

\section{LA PERSONALIDAD EXTENDIDA: LAS PRÁCTICAS MORTUORIAS Y LA TRANSFORMACIÓN DE LA PERSONA}

El vestido y los objetos - las armas y los ornamentos corporales- asociados al muerto han sido usados por los arqueólogos de dos maneras. En primer lugar, como evidencia documental para analizar la persona social del difunto: los modos específicos de vestir y ornamentar el cuerpo funcionarían como pieles sociales (Turner 1993), que se corresponderían con diferentes categorías sociales y, por tanto, permitirían leer la identidad en este ámbito del individuo. De este modo, los mecanismos de demarcación e inscripción de la superficie del cuerpo son puntos de rearticulación entre la identidad propia e interna de un individuo y la sociedad exterior.
Esta idea, que recorre gran parte de la imaginación arqueológica, responde a una concepción metafísica del pensamiento moderno. La identidad y la personalidad son elementos fijos, esenciales, dados a priori al individuo y que, por tanto, toda la parafernalia objetual asociada al mismo simplemente refleja esas condiciones dadas.

En los años ochenta, como reacción a la Arqueología moderna y a sus categorías analíticas globales -pueblos, culturas, sistemas sociales, etc.-, el postprocesualismo intentó recuperar la idea de un individuo como agente histórico y objeto de estudio. Este nuevo interés, más allá de considerar al individuo un simple reflejo del sistema (Hill-Gunn 1977), pretendió remarcar su dimensión como actor social (Hodder 1986: 6; véase Johnson 1989). La adopción de presupuestos de la Teoría de la práctica (Bourdieu 1977; Giddens 1979) y la importancia que cobra el cuerpo en el discurso arqueológico a través de la fenomenología y de la idea de embodiment (Hamilakis et al. 2002; Joyce 2005; Boric y Robb 2008; Tilley 2008), matizó la capacidad activa que Hodder quiso asignar al individuo en la reproducción social. Las teorías de Bourdieu y Giddens tuvieron importantes implicaciones para los arqueólogos, al señalar el papel que los individuos, como agentes, tienen en la producción y reproducción de las estructuras (Barrett 2001; Dobres y Robb 2000; 2005; Dornan 2002; Gardner 2004).

La tendencia general fue asumir que las intenciones son movilizadas e inducidas por el conjunto de reglas, patrones y dispositivos materiales que constituyen el campo de discurso en el que se encuentra inserto el individuo. De este modo, por ejemplo, la ropa, los adornos y las armas, más que reflejar identidades sociales adquiridas de antemano, son dispositivos que ayudan a crear parte de las condiciones de los individuos, y, por tanto, forman tipos específicos de personas. En este contexto, algunos autores rechazan la idea de que la superficie del cuerpo funciona como espacio público donde se muestra el estatus de los individuos. En su lugar, consideran que existen prácticas corporales en las que se hibridan el cuerpo y los objetos como un modo activo de crear identidades (Treherne 1995; Sørensen 1997; Matthews 2004a; 2004b; Stevens 2007).

Desde esta perspectiva, la relación que se establece entre el cuerpo, la vestimenta y los objetos de adorno, posibilita la construcción activa de la identidad (Fisher y Loren 2003). Por ejemplo, Treherne (1995) interpreta los artículos de belleza y de cuidado personal que aparecen en las tumbas de la Edad del Bronce -pinzas, navajas de afeitar, armas, objetos de adorno, etc.- como 
elementos constitutivos y creadores de identidad, y no como un reflejo de la misma. En este sentido, el ideal del guerrero masculino de la Edad del Bronce no puede ser posible sin las affordances de los nuevos materiales. La identidad, tal como la entiende Sørensen, no hace referencia simplemente a las características asumidas por el grupo y asignadas a un individuo concreto. La cultura material produce y reproduce la identidad, de modo que no debe ser estudiada como mero índice de hombres y mujeres; esto es, de definiciones de la persona previamente dadas. Es por esta razón por la que Sørensen (2000: 140) afirma que ciertas identidades sociales que no se corresponden con esta dicotomía masculino/femenino han sido ignoradas en la investigación de la Edad del Bronce europea. De este modo, el uso que hace de la noción de identidad es diferente, por ejemplo, a la idea de identidad como algo subjetivo y propio de un individuo. En ambos casos -ya sea tras la idea de la piel social, ya a través de la idea de que las prácticas corporales crean la identidad-, la noción de individuo se correlaciona con la noción de persona y con una imagen estable de la identidad que acompaña a toda persona a lo largo de su vida. En el propio seno del postprocesualismo se han señalado los problemas que supone la aplicación de esta correlación fuera del contexto occidental (Knapp y Meskell 1997: 189; Thomas 2004; Fowler 2004; Knapp y Van Dommelen 2008).

El individuo es «un tipo cultural particular (de persona) más que una categoría analítica autoevidente» (Strathern 1981: 168). Tras esta noción se encuentra la ecuación cartesiana que iguala y establece la correlación entre persona, yo y conciencia (Mauss 1938), que ha permitido conceptualizar la idea de persona como una entidad estable y bien definida con límites impermeables, con un núcleo esencial y unificado (el individuo). Aunque en el seno de la tradición occidental sea difícil separar al individuo de la persona, esta correspondencia es ajena a muchas comunidades pretéritas y no occidentales que tienen concepciones diferentes de la idea de individuo y, por tanto, del cuerpo y de la muerte.

Dos críticas claves permiten comprender el abandono postprocesual de la conceptualización que iguala individuo-persona: (1) la idea de la identidad como algo estable y esencial que acompaña al sujeto toda su vida; y (2) la dicotomía objeto-sujeto. El primer axioma es deconstruido como un ideal normativo occidental. Diversos arqueólogos (Thomas 2000: 658; 2004: 215-216; Gosden 1999; Fowler 2000; 2002: 48-50; Joyce 2005: 145-147; Perry y Joyce 2001), siguiendo los planteamientos de Butler (1993), cuestionan que las identidades sean autoidénticas, persistentes en el tiempo y coherentes internamente. Al discutir la diferenciación entre sexo y género, Butler denuncia cómo el último término, al ser considerado social y culturalmente construido, refuerza la idea de que el primero es el elemento dado a priori, reproduciendo la dicotomía naturaleza-cultura. Bajo esta perspectiva, el sexo constituye el fondo biológico y material invariable sobre el que se amolda luego el género. Para Butler, el cuerpo biológico (sexual), al margen de la construcción cultural, es un producto de las metafísicas occidentales (Olsen 2010: 56). Su teoría performativa ha servido a los arqueólogos para deconstruir la metafísica implícita en la Arqueología moderna en relación a la identidad.

Joyce señala lo peligroso que es traspasar nuestro ideal normativo occidental al pasado y asumir que «el sexo fue siempre la parte más importante de las identidades de las gentes en el pasado» (Joyce 2008: 49; véase también Yates y Nordbladh 1990; Sørensen 1991). Para esta arqueóloga, si uno busca diferencias entre el hombre y la mujer en los contextos funerarios, frecuentemente encontrará modos de discriminar entre estos dos grupos. Pero quizás, la asunción previa de que lo que importa es una distinción binaria oscurece otros modos más importantes que las comunidades del pasado utilizaron para establecer la diferencia. Por ejemplo, a través de estudios bioarqueológicos y contextuales del registro funerario de los Chumash (Santa Bárbara, California), Hollimon determinó que el sexo no podía haber sido la base más significativa para la identidad de estos grupos sociales (Hollimon 1997; 2006). Los géneros no fueron identidades categoriales permanentes, y aunque estaban relacionadas con la sexualidad, podían cambiar a lo largo de la vida de una persona. Lo que nosotros comprendemos como las características sexuales biológicas no tienen por qué ser comprendidas de igual modo en otros contextos ni modernos ni occidentales (Moore 1994: 6; Meskell 1998: 141).

La segunda crítica se centró en el uso que la Arqueología ha hecho de la dicotomía objeto-sujeto -característica del pensamiento moderno occidental-, y que obscurece otras posibles lógicas no occidentales de tipo relacional, como hemos visto en apartados anteriores. Se ha señalado que las teorías de la objetivación y las aproximaciones fenomenológicas, a pesar de su intención de superar este problema, han fracasado en su intento (Brück 2001; Ingold 2007). En este sentido, Brück (2001: 651) considera que el tipo de personas que parece haber sido producido en los contextos monumentales neolíticos, según estas posiciones teóricas, continúa manteniendo similitudes con el concepto de yo específico del mundo occidental moderno. En muchas 
sociedades, al no funcionar esta dicotomía, el poder de la causación reside fuera del individuo humano (BirdDavid 1999; Descola 1992; Harvey 2006; Viveiros de Castro 1998; 2004; Stringer 1999: Watts 2013).

La Arqueología de la Muerte se ha visto transformada por el surgimiento de una Arqueología de la Identidad que ha roto con la ecuación que iguala individuo, persona e identidad. En este tipo de aproximación, se distingue entre la idea de individuo como una conceptualización biológica del ser humano, y las ideas de yo y de persona como conceptualizaciones psicológicas (como locus de experiencia) y sociológicas (como un agente en sociedad) respectivamente (Budja 2010). De este modo, la solución al problema ha pasado por sustituir, como categoría analítica, la idea de individuo por la noción de personalidad, lo que ha permitido hacer hincapié en las diferentes formas de identidad que pudieron haber funcionado en el pasado. Fowler (2004: 155) define la personalidad como «la condición de ser de una persona conceptualizada por una comunidad dada». Aquí se subrayan por tanto dos cuestiones: por un lado, la importancia del componente social y colectivo de la identidad sobre la idea de individuo como actor; y por otro, que la personalidad no está confinada a los seres humanos vivos, permitiendo remarcar las relaciones «entre diferentes personas, personas y grupos, diferentes grupos, los vivos y los muertos, y la personas y los objetos» (Gillespie 2001: 75).

La Arqueología ha recurrido a los diferentes modelos de personalidad relacional de la Antropología melanesia e hindú para analizar los contextos funerarios. La comprensión dividual, partible (Strathern 1988), fractal (Wagner 1991) o permeable (Busby 1997) de la persona, permite así crear modelos alternativos al occidental, y repensar la idea de identidad. De forma general, bajo una concepción de este tipo, una persona se constituye como tal a través del conjunto de relaciones en las que se halla implicada, y a través de las cuales se incardina en el mundo. La percepción dividual, por tanto, enfatiza que cada persona es un compuesto de substancias y acciones de otros. Cada persona engloba múltiples cosas y relaciones constituyentes de otras personas, así las personas se ven afectadas por procesos de interacción. La persona, bajo esta perspectiva, no es fija ni indivisible sino «una incorporación flexible de diferentes cualidades y relaciones» (Fowler 2010: 140). No solo las sustancias son parte de cada persona, sino que los objetos e incluso los animales son incorporados a la persona a través del intercambio. La personalidad dividual o relacional puede ser permeable en vez de partible. En este caso, las partes que componen la persona no son identificables como objetos sino como flujo de substancias: «las partes del cuerpo no se mantienen como objetos especificos en lugares distantes, sino permean el universo generalmente, enviándolos al cielo o al fondo de los ríos» (Fowler 2004: 82).

La importancia del estudio y definición de la personalidad para la Arqueología de la Muerte radica en el hecho de que, dependiendo del modo de personalidad que funcione en cada contexto, tendremos modos diferentes de producir la muerte. Es decir, si la muerte es un proceso de transformación de la persona (Alfayé 2009: 183; Van Gennep 2008; Hertz 1960), la conceptualización y sentido de esta transformación viene dada por las comprensiones de la personalidad que rigen en cada contexto. La muerte no es una inversión de la vida sino parte de la negociación social de la misma. De este modo, las prácticas mortuorias son interpretadas como procesos que deconstruyen la persona a través de la producción de su muerte, y ofrecen la oportunidad para la reconstitución de las relaciones sociales entre los vivos, y de estos con los muertos. Esto permite superar la concepción occidental como único modelo, que considera el tratamiento de la muerte como un acto de conservación de la memoria de la persona mediante el mantenimiento de su cuerpo intacto, donde reside la personalidad (Fowler 2004: 96). Así, los espacios mortuorios se han convertido en dispositivos de análisis de especial relevancia para la Arqueología postmoderna al permitir deconstruir dentro de la imaginación arqueológica la idea de individuo como categoría transcultural y con una identidad estable y esencial, e indagar modos de personalidad relacional diferentes al occidental.

En muchos depósitos funerarios megalíticos del Neolítico europeo se documentan acumulaciones de fragmentos óseos desarticulados y esparcidos, que en ocasiones van acompañados por cuerpos completamente articulados. La explicación tradicional afirma que el uso prolongado de estos espacios supuso sucesivas inhumaciones que obligaban a apartar o retirar los restos óseos de las viejas inhumaciones para dejar espacio para nuevos enterramientos. Sin embargo, Thomas ve en ese escenario formado por huesos desarticulados y articulados anatómicamente «una metáfora del estado cambiante de las personas» (Thomas 2000: 659). A menudo, los cuerpos fueron introducidos en las cámaras funerarias, y sus esqueletos procesados y desarticulados en el interior. En otros casos, se constata que algunos restos óseos habían estado previamente depositados en otros lugares. Thomas plantea por primera vez que la introducción y extracción de los 
huesos en las estructuras mortuorias podría responder a un patrón más amplio de circulación en la que también están implicados otros materiales (Thomas 1998: 78-80; 2000: 660; 2002: 42). Compara esta «economía de sustancias» con la circulación de objetos en las economías de don, en las que en ocasiones los artefactos son interpretados como parte de una persona o de su cuerpo, lo que permite construir relaciones sociales a través del don y del contra don. Desde esta lógica, la circulación de partes del cuerpo en momentos de la Prehistoria puede concebirse «como un flujo, segmentado por una serie de transacciones». La fosilización de esta circulación la encuentra en los restos óseos que durante la Prehistoria Reciente fueron depositados en multitud de lugares: fosos, fosas, ríos, cuevas, etc. (Rebay-Salisbury et al. 2010).

De esta manera los espacios mortuorios neolíticos no eran solo un espacio de vínculo con los antepasados, sino también un lugar para la descomposición del cuerpo y para posteriores operaciones sobre el mismo. Por tanto, un lugar de transición y transformación que permite que los huesos puedan entrar en circulación, pasar de una persona a otra, llevarse de un lugar a otro, o ser depositados en lugares significativos. La circulación y deposición de los restos óseos establecen la presencia del muerto a través del paisaje. Se trata pues, según Thomas (2000: 662), de lugares en donde «las categorias de personalidad fueron disueltas y recreadas».

Chapman (2000a; 2000b) ha aplicado las concepciones relacionales de la personalidad al Neolítico y el Calcolítico de los Balcanes. Los huesos humanos, los objetos y los artefactos fragmentados, a través de procesos paralelos de encadenamiento y de acumulación vinculados al difunto, más que simbolizar parentesco (véase Carsten 2004), directamente lo crean. Así, para Chapman, las personas neolíticas fueron encadenadas por objetos inalienables creando personalidades de tipo dividual. Chapman y Gaydarska (2007) reconceptualizan la visión fractal y partible de la personalidad de Strathern (1988) y Wagner (1991). El traslado de huesos a otros contextos mortuorios y domésticos redefine las relaciones sociales entre los vivos y los muertos, que se convierten en ancestros al mantener viva su esencia a través de la materialidad de sus huesos. La práctica de la manipulación y el traslado selectivo de partes del cuerpo, con o sin recombinación, es «una afirmación de la continuidad de las relaciones sociales» (Chapman 2000a: 144). Del mismo modo, la fragmentación deliberada de objetos y su recomposición (curación), indica un concepto fractal de la personalidad y de las relaciones sociales. Ambos autores comparan estos objetos partidos con la fragmentación de los cuerpos, y analizan la relación entre las partes y el todo -hueso/esqueleto, tumba/cementerio, objeto/tesoro- como principio fractal que permite estructurar las relaciones y negociar las identidades y la personalidad. Mientras los procesos de encadenamientos de sustancias inalienables producen relaciones fractales y partibles, los procesos de acumulación de objetos alienables intactos (sanos) posibilitan personalidades más individualizadas. De este modo, la identidad individualizada, lejos de ser inherente a las personas, es un logro social (Chapman y Gaydarska 2007: 199-202).

El reconocimiento de que los aspectos constitutivos de la personalidad en el pasado difieren de $-\mathrm{y}$ son incompatibles con- las nociones occidentales de individuo e identidad, tiene consecuencias directas en el modo en que se debe entender la propia idea de agency. Brück ha señalado que si las personas están constituidas a través de sus relaciones con otros (humanos y no-humanos), entonces ellos nunca podrán conceptualizarse como agentes libres en el sentido liberal y occidental. La agency, en estos casos, no está localizada simplemente dentro de los cuerpos humanos, sino dentro del amplio conjunto de relaciones sociales que constituyen a la persona (Brück 2001).

La vena crítica y la deconstrucción de la metafísica del pensamiento moderno, y la búsqueda de modelos alternativos a través de ideas como la personalidad relacional o los objetos biográficos, han propiciado que el estudio de la muerte en Arqueología haya adquirido lo que ha sido descrito recientemente como un melanesian flavour (Jones 2005: 195), que ha sido criticado por algunos autores (Whitley 2002; Spriggs 2008). De hecho, en la última década, la idea de que la circulación y distribución de fragmentos del cuerpo del difunto y de los objetos vinculados a sus vidas actúan como metáfora para la naturaleza dividual de la persona, se ha esgrimido para reinterpretar depósitos y contextos funerarios desde el Mesolítico hasta la Edad Media (Fahlander 2008; Nilsson-Stutz 2003; Berggren y Nilsson-Stutz 2010; Brück 2001; 2006; Fowler 2004; 2007; 2008; 2010; Guerrero et al. 2009; Graham 2009; Kuijt 2008; Nilsson-Stutz 2003; Lally y Ardren 2008; Bazelmans 2000; 2002). En todos estos trabajos se asume que la muerte, la descomposición, la fragmentación corporal intencional, y la circulación de objetos y restos humanos deben de haber sido parte fundamental de los procesos de socialización de muchos grupos sociales. 


\section{CONCLUSIÓN}

A través de este artículo, hemos pretendido mostrar cómo los debates y los nuevos conceptos, metáforas y modos de pensar introducidos en la teoría arqueológica, han guiado las diferentes aproximaciones al estudio del registro funerario. En este sentido, en la historia de la Arqueología encontramos dos modos básicos de aproximación a la muerte: una Arqueología moderna, que engloba al historicismo cultural y a la Nueva Arqueología, que sienta las bases de la Arqueología como disciplina; y otra postmoderna, que encierra la propia Arqueología postprocesual y que somete a la disciplina a un adelgazamiento metafísico, haciéndola operativa en el contexto político y cultural actual.

En el primer caso, el historicismo cultural utilizó los datos del registro material como marcadores materiales de pueblos y culturas en el contexto del surgimiento y la consolidación de los estados-nación; mientras que la Nueva Arqueología los usó como índices de los diferentes niveles económicos, sociales y políticos en el marco de la evolución de la sociedad humana, en el contexto de las teorías neoevolutivas y el desarrollo económico y social del primer mundo tras la Segunda Guerra Mundial. En ambos casos, el registro funerario, como documento arqueológico, fue asumido como un reflejo del pasado; y las prácticas funerarias que se hallan tras ese registro material fueron consideradas como una expresión pasiva de los sistemas de creencias o de las estructuras sociales, y como marcadores sobre el terreno de pueblos y culturas, o de áreas de captación y de recursos esenciales, respectivamente. El postprocesualismo, frente a la actitud especular del pensamiento moderno, recurre a los restos materiales de las prácticas rituales como elementos propicios para deconstruir la imaginación moderna del pasado. Asimismo, los rituales mortuorios y las prácticas materiales pasan a ser consideradas como elementos activos en la construcción social de las comunidades pretéritas. La concepción hodderiana, planteada hace tres décadas, de que la cultura material es significativamente constituida, abrió el camino a los nuevos modos de interpretar el registro funerario que acabamos de analizar, permitiendo así subrayar el papel activo, estructurante, sinestésico y performativo de las prácticas y los espacios funerarios en la construcción de las sociedades.

La propia actitud deconstructiva de la Arqueología de la muerte postprocesual es también, como hemos tenido ocasión de ver, el punto de partida de nuevas lecturas e interpretaciones del registro funerario. Aquí reside una de las grandes diferencias respecto a la imaginación arqueológica previa. En las tendencias modernas, el valor epistemológico de sus explicaciones radica en la coherencia y concordancia con el pasado, esto es, en su capacidad para descubrir un pasado (real) y en su poder para explicarlo (tal como fue). En las Arqueologías postprocesuales, sin embargo, al asumir una actitud postmoderna $-\mathrm{y}$, por tanto, hacer suya su crítica de la idea de verdad-, las interpretaciones adquieren valor, en gran medida, no tanto por sacar a la luz un pasado real, sino por su capacidad para -o su intención dedesestabilizar la metafísica dualista de la Arqueología histórico-cultural y procesual y, por extensión, del pensamiento moderno. De este modo, la Arqueología de la Muerte postprocesual lleva a cabo en su terreno epistémico lo que el proyecto postmoderno globalmente pretende en el contexto cultural e intelectual occidental: en primer lugar, deconstruir las metafísicas dualistas sobre la que se configura la razón moderna -pasado/presente, sujeto/objeto, activo/pasivo, cultura/naturaleza, etc.--; y en segundo lugar, establecer, interpretaciones alternativas y nuevas filosofías del dato que sirvan de contrapunto a los metarrelatos modernos y a sus modos de construir la información arqueológica. En suma, está filtrando al pasado las nuevas sensibilidades y concepciones propias de la lógica cultural del capitalismo avanzado y de la sociedad postcolonial actual, en relación al individuo, las identidades, la memoria, o el papel que la cultura material juega en nuestras vidas. Para ello, el postprocesualismo ha recurrido a un gran conjunto de aproximaciones y ha encontrado en los diferentes conceptos y metáforas que acabamos de analizar los modos de acometer este trabajo.

Como señalamos al principio de este texto, la Arqueología como saber es una elaboración secundaria de nuestra sociedad y, por tanto, internaliza la agenda política y cultural del arqueólogo y de su contexto intelectual y social. De esta forma, el modo de abordar el registro funerario en la historia de la imaginación arqueológica nos da una imagen de los valores y preocupaciones de nuestra sociedad. Pero esto no significa que sea un reflejo pasivo de ella. Al contrario, debemos comprenderla como un dispositivo discursivo y material que ayuda a construir y legitimar un modo concreto de comprender el mundo.

La Nueva Arqueología, en su vena sistémica y en su concepción positivista, buscó una teoría del rango medio que limpiara la Arqueología, y el propio funcionamiento de las sociedades, de los componentes emocionales y contextuales que impiden establecer lógicas causales transculturales. Uno de los objetivos de la Arqueología teórica a partir de los años ochenta del 
siglo XX fue restituir esos elementos en el discurso. De modo llamativo, el Postprocesualismo, siendo una reación a una Arqueología cuya hegemonía duró una década - los años setenta-, ha terminado dominando la teoría durante las tres siguientes décadas; tres veces más que aquella frente a la que reaccionó. En cierto modo, este lapso de tiempo no solo ha servido para deconstruir el pensamiento procesual, sino, como hemos visto, también para que la Arqueología Postprocesual se deconstruyera, recursivamente, a sí misma. El cansancio provocado por la prolongación en el tiempo de este post- puede explicar que recientemente se hayan planteado posiciones teóricas que, aunque se entroncan con el postprocesualismo, se autoposicionan más allá de él. Es el caso de la Arqueología Simétrica (Shanks 2007), reflejo de la propia escisión y avance respecto al Postmodernismo, propuesta por Latour en Antropología, al señalar que, en realidad, «nunca hemos sido modernos», ya que la cultura moderna jamás ha sido enteramente lograda. Para este autor, la modernidad es una ficción en tanto que «ha faltado clamorosamente a la cita con la realidad». Sintomáticamente, considera que, por tanto, «nunca seremos postmodernos» (Latour 1993: 97-103). Latour rechaza una postmodernidad que se propone ir más allá de lo que nunca ha existido, pero cuya gran aportación, con todo, ha sido permitirnos precisamente tomar conciencia de ello. En todo caso, debemos esperar todavía para saber si en este contexto de negación del fundamento postmoderno del postprocesualismo se abrirá una nueva fase para la Arqueología de la Muerte.

\section{BIBLIOGRAFÍA}

Alfayé, S. (2009): "Sit tibi terra gravis: Magical-ritual Practices against Restless Dead in the Ancient World", en F. Marco, F. Pina y J. Remesal (eds.), Formae mortis. El tránsito de la Vida a la Muerte en las Sociedades Antiguas: 181-216. Barcelona, Universitat de Barcelona.

Alfayé, S. (2010): "Nails for the Dead: A Polysemic Account of an Ancient Funerary Practice", en R. L. Gordon y F. Marco Simón (eds.), Magical Practice in the Latin West: 427-456. Leiden, Brill.

Alfayé, S. (2011): Imagen y ritual en la Céltica peninsular. A Coruña, Toxosoutos.

Appadurai, A. (1986): "Introduction: commodities and the politics of value", en A. Appadurai (ed.), The Social Life of Things: Commodities in cultural perspective: 3-63. Cambridge, Cambridge University Press.
Bailey, G. (2007): "Time perspectives, palimpsests and the archaeology of time". Journal of Anthropological Archaeology 26: 198-223. https://doi. org/10.1016/j.jaa.2006.08.002

Bapty, I. y Yates, T. (eds.) (1990): Archaeology after structuralism. London, Routledge.

Barrett, J.C. (1987): "Contextual Archaeology". Antiquity 61: 468-73. https://doi.org/10.1017/ S0003598X00073087

Barrett, J.C. (1988): "The living the dead and the ancestors: Neolithic and Early Bronze Age mortuary practices», en J.C. Barrett y I. A. Kinnes (eds.), The Archaeology of Context in the Neolithic and Bronze Age: Recent Trends: 30-4. Sheffield, J.R. Collis Publications.

Barrett, J.C. (1994): Fragments from Antiquity: An Archaeology of Social Life in Britain, 2900-1200 BC. Oxford, Blackwell.

Barrett, J.C. (2001): “Agency, the duality of structure, and the problem of the archaeological record", en I. Hodder (ed.), Archaeological Theory Today: 140164. Oxford, Polity.

Barrett, J. y Fewster, J. (2000): "Intimacy and structural transformation: Giddens and Archaeology", en C. Holtorf y H. Karlsson (eds.), Philosophy and archaeological practice: 25-38. Göteborg, Bricoleur Press.

Bazelmans, J. (2000): "Beyond Power: Ceremonial Exchanges in Beowulf", en F. Theuws y J. L. Nelson (eds.), Rituals of Power from Late Antiquity to the Early Middle Ages: 311-75. Leiden, Brill.

Bazelmans, J. (2002): "Moralities of Dress and the Dress of the Dead in Early Medieval Europe", en Y. Hamilakis, M. Pluciennik y S. Tarlow (eds.), Thinking through the Body: Archaeologies of Corporeality: 71-84. New York, Springer.

Becker, E. (1973): The denial of death. New York, Free Press.

Belcastro, M.G. y Ortalli, J. (curs.) (2010): Sepolture anomale. Indagini archaeologiche e antropologiche dall'epoca classica al Medioevo in Emilia Romagna. Bologna, All'Insegna del Giglio.

Bender, B. (1998): Stonehenge: Making Space. Oxford, Berg.

Berggren, A. y Nilsson Stutz, L. (2010): "From spectator to critic and participant: A new role for archaeology in ritual studies". Journal of Social Archaeology 10 (2): 171-197. https://doi. org/10.1177/1469605310365039

Binford, L. (1971): "Mortuary Practices: their Study and their Potential", en J. A. Brown (ed.), Approaches to 
the Social Dimensions of Mortuary Practices: 6-29. Washington, Society for American Archaeology.

Binford, L. (1977): "Introduction”, en L. Binford (ed.), For Theory Building in Archaeology: 1-10. New York, Academic Press Inc.

Bird-David, N. (1999): "Animism revisited: personhood, environment and relational epistemology". Current Anthropology 40: 67-79.

Boivin, N. (2004): "From veneration to exploitation: human engagement with the mineral world", en N. Boivin y M. A. Owoc (eds.), Soils, stones and symbols: cultural perceptions of the mineral world: 165-186. London, Psychology Press.

Boivin, N. (2008): Material Cultures, material minds. Cambridge, Cambridge University Press.

Boivin, N. y Owoc, A. (eds.) (2004): Soils, stones and symbols: cultural perceptions of the mineral world. London, Psychology Press.

Boric, D. (2002): "Apotropaism and the Temporality of Colours: Colourful Mesolithic-neolithic Seasons in the Danube Gorges", en A. Jones y G. MacGregor (eds.), Colouring the Past: The Significance of Colour in Archaeological Research: 23-44. Oxford: Bloomsbury Publishing.

Boric, D. (2003): "Deep time metaphor: mnemonic and apotropaic practices at Lepenski Vir". Journal of Social Archaeology 3(1): 46-74. https://doi. org/10.1177/1469605303003001098

Borric, D. (ed.) (2010): Archaeology and Memory. Oxford, Oxbow.

Boric, D. y Robb, J. (eds.) (2008): Past Bodies: BodyCentered Research in Archaeology. Oxford, Oxbow.

Bourdieu, P. (1977): Outline of a Theory of Practice. Cambridge, Cambridge University Press.

Bradley, R. (1989): "Darkness and light in the design of megalithic tombs". Oxford Journal of Archaeology 8: 251-259. DOI: 10.1111/j.1468-0092.1989. tb00205.x

Bradley, R. (1993): Altering the Earth: the origins of monuments in Britain and continental Europe. Edinburgh, Society of Antiquaries of Scotland.

Bradley, R. (1998): The significance of monuments. London, Routledge.

Bradley, R. (2000): An Archaeology of Natural Places. London, Routledge.

Bradley, R (2000a): "Death and the regeneration of life: a new interpretation of house urns in Northern Europe". Antiquity 76: 372-377. https://doi. org/10.1017/S0003598X00090463

Bradley, R. (2002b): The past in prehistoric societies. London, Routledge.
Bradley, R. (2009): Image and audience: rethinking prehistoric art. Oxford, Oxford University Press.

Brown, J. (1995): “On Mortuary Analysis with Special Reference to the Saxe-Binford Research Program", en L. A. Beck (ed.), Regional Approaches to Mortuary Analysis: 3-26. New York, Springer.

Brown, J. A. (ed.) (1971): Approaches to the social dimensions of mortuary practices. Washington, Society for American Archaeology.

Brück, J. (2001): "Monuments, power and personhood in the British Neolithic". Journal of the Royal Anthropological Institute 7: 649-668. DOI: 10.1111/1467-9655.00082

Brück, J. (2006): "Material metaphors. The relational construction of identity in Early Bronze Age burials in Ireland and Britain". Journal of Social Archaeology 4 (3): 307-333. DOI: 10.1177/1469605304046417

Buchli, V. (2002): "Introduction”, en V. Buchli (ed.), The material culture reader: 1-22. Oxford, Berg.

Budja, M. (2010): "The archaeology of death from social personae to relational personhood". Documenta Praehistorica XXXVII: 43-54. http://dx.doi. org/10.4312/dp.37.4

Busby, C. (1997): "Permeable and partible persons: A Comparative Analysis of Gender and Body in South India and Melanesia". Journal of Royal Anthropological Institute 3: 261-278. http://www.jstor.org/ stable/3035019

Butler, J. (1993): Bodies that Matter: on discursive limits of sex. New York, Routledge.

Carsten, J. (2004): After Kinship. Cambridge, Cambridge University Press.

Casella, E.C. y Fowler, C. (2005): The archaeology of plural and changing identities: beyond identification. New York, Springer.

Chapa Brunet, T. (1991): "La Arqueología de la Muerte: planteamientos, problemas y resultados", en D. Vaquerizo Gil (coord.), Arqueología de la Muerte: Metodología y perspectivas actuales: 1338. Córdoba, Excma. Diputación Provincial de Córdoba.

Chapa Brunet, T. (2006): “Arqueología de la Muerte: Aspectos metodológicos". Anales de Arqueología Cordobesa 17: 25-46.

Chapman, J. (2000a): Fragmentation in Archeology, People, places and broken objects in the prehistory of southeastern Europe. London, Routledge.

Chapman, J. (2000b): Tensions at Funerals: MicroTransition Analysisin Later Hungarian Prehistory. Budapest, Archaeolingua. 
Chapman, J. y Gaydarska, B. (2007): Parts and wholes: fragmentation in prehistoric context. Oxford, Oxbow.

Chapman, R. (1981): "The emergence of formal disposal areas and the 'problem' of megalithic tombs in prehistoric Europe", en R. Chapman, I. Kinnes y J. Randsborg (eds.), The Archaeology of Death: 7182. Cambridge, Cambridge University Press.

Chapman, R. (2003): Archaeologies of Complexity. London, Routledge.

Chapman, R.; Kinnes, I. y Randsborg, K. (eds.) (1991): The archaeology of Death. Cambridge, Cambridge University Press.

Chapman, R. y Randsborg, K. (1981): “Approaches to the Archaeology of Death", en R. Chapman, I. Kinnes y K. Randsborg (eds.), The archaeology of Death: 1-24. Cambridge, Cambridge University Press.

Charlier, P. (2009): Male mort. Morts violentes dans l'Antiquité. Paris, Fayard.

Childe, V. G. (1929): The Danube in Prehistory. Oxford, Clarendon Press.

Childe, V. G. (1940): Prehistoric Communities of the British Isles. London, W. \& R. Chambers.

Cochrane, A. (2005): "A taste for the unexpected: subverting mentalite's through the motifs and settings of Irish passage tombs", en D. Hofmann, J. Mills, y A. Cochrane (eds.), Elements of Being: Mentalite's, Identities and Movement: 5-19. Oxford, British Archaeological Reports Oxford.

Cochrane, A. (2006): "The simulacra and simulations of Irish Neolithic passage tombs", en I. Russell (ed.), Images, Representations and Heritage: Moving Beyond a Modern Approach in Archaeology: 251-282. New York, Springer.

Cochrane, A. (2007): "We have never been material", en J. Thomas y V. O. Jorge (eds.), Overcoming the modern invention of material culture (Proceedings of the TAG session. Exeter 2006): 137-158. Porto, ADECAP.

Dawson, W. R. (1928): "Mummification in Australia and in America". Journal Royal Anthropological Society of Great Britain and Ireland 58: 115-138.

Descola, P. (1992): "Societies in nature and the nature of society", en A. Kuper (ed.), Conceptualizing Society: 107-126. Cambridge, Cambridge University Press.

Dobres, M.-A. y Robb, J. E. (eds.) (2000): Agency in Archaeology. London, Routledge.

Dobres, M.-A. y Robb, J. E. (2005): "Doing agency: introductory remarks on methodology". Journal of Archaeological Method and Theory 12: 159-166. https://doi.org/10.1007/s10816-005-6926-z
Dornan, J. L. (2002): “Agency and archaeology: past, present and future directions". Journal of Archaeological Method and Theory 9: 303-329. https://doi. org/10.1023/A:1021318432161

Douglas, M. (1966): Purity and danger. An analysis of the concepts of pollution and taboo. London, Routledge

Dowd, M. y Hensey, R. (eds.) (2016), The Archaeology of Darkness. Oxford, Oxbow.

Dronfield, J. (1995): "Subjective Vision and the Source of Irish Megalithic Art". Antiquity 69: 539-549. https://doi.org/10.1017/S0003598X00081928

Dronfield, J. (1996): "Entering alternative realities: cognition, art and architecture in Irish passage tombs". Cambridge Archaeological Journal 6 (1): 37-72.

Eckardt, H. y Williams, H. (2003): “Objects without a past?”, en H. Williams (ed.), Archaeologies of remembrance:141-170. New York, Springer.

Edmonds, M. (1995): Stone Tools and Society. London, Batsford.

Edmonds, M. (1999): Ancestral Geographies of the Neolithic. London, Routledge.

Eliade, M. (1960): El Chamanismo y las técnicas arcaicas del éxtasis. México, Fondo de Cultura Económica.

Fahlander, F. (2003): The materiality of serial practice: a microarchaeology of burial. Göteborg, Göteborg University.

Fahlander, F. (2008): "A Piece of the Mesolithic Horizontal Stratigraphy and Bodily Manipulations at Skateholm", en F. Fahlander y T. Oestigaard (eds.), The Materiality of Death: Bodies, Burials, Beliefs: 29-46. Oxford, Oxbow.

Ferrer Albelda, E.; Lozano, F. y Mazuelos, J. (coords.) (2009): Salvación, infierno y olvido. Escatología en el mundo antiguo. Spal Monografías XIV. Sevilla, Universidad de Sevilla.

Fisher, G. D. y Loren P. (2003): “Embodying Identity in Archaeology". Cambridge Archaeological Journal 13 (2): 225-230. DOI: 10.1017/ S0959774303210143

Flannery, K. V. (1967): "Culture history versus culture process: A debate in American Archaeology". Scientific American 217: 119-122.

Fleming, A. (1973): "Tombs for the living". Man 8: 177-193.

Foucault, M. (2000): Vigilar y Castigar. Madrid, Biblioteca Nueva.

Fowler, C. (2000): “The individual, the subject, and archaeological interpretation: reading Luce Irigaray and Judith Butler", en C. Holtorf y H. 
Karlsson (eds.), Philosophy and Archaeological Practice: Perspectives for the 21st Century: 10733. Gothenburg, Bricoleur Press.

Fowler, C. (2002): "Body parts: personhood and materiality in the earlier Manx Neolithic", en Y. Hamilakis, M. Pluciennik y S. Tarlow (eds.), Thinking Through the Body: Archaeologies of corporeality: 47-69. New York, Springer.

Fowler, C. (2004): The Archaeology of Personhood: An Anthropological Approach. London, Routledge.

Fowler, C. (2007): "Landscape and personhood", en B. David y J. Thomas (eds.), Handbook of Landscape Archaeology: 291-299. California, Left Coast Press.

Fowler, C. (2008): "Fractal bodies in the past and present", en D. Boric y J. Robb (eds.), Past Bodies: Body-Centred Research in Archaeology: 47-57. Oxford, Oxbow.

Fowler, C. (2010): "Relational personhood as a subject of anthropology and archaeology: comparative and complementary analyses", en D. Garrow y T. Yarrow (eds.), Archaeology and anthropology: understanding similitary, exploring difference: 137159. Oxford, Oxbow.

Frazer, J. G. (1886): “On certain burial customs as illustrate of the primitive theory of the soul". Journal of the Anthropological Institute of Great Britain and Ireland 15: 64-104.

Freud, S. (1967): Tótem y tabú. Madrid, Alianza Editorial.

Gadamer, H-G. (1977): Verdad y método. Salamanca, Ediciones Sígueme.

García Sanjuán, L. y Wheatley, D.W. (2010): "Natural substances, landscape forms, symbols and funerary monuments: elements of cultural memory among the Neolithic and Copper Age societies of southern Spain”, en T. Lillios y V. Tsamis (eds.), Material Mnemonics: everyday memory in prehistoric Europe: 10-39. Oxford, Oxbow.

Gardner, A. (2004): Agency Uncovered: Archaeological Perspectives on Social Agency, Power and Being Human. London, University College London Institute of Archaeology Publications.

Garrow, D. y Yarrow, T. (eds.) (2010): Archaeology and anthropology: understanding similitary, exploring difference. Oxford, Oxbow.

Gell, A. (1992): "The technology of enchantment and the enchatment of technology", en J. Coote y A. Shelton (eds.), Anthropology, art and aesthetics: 40-67. Oxford, Clarendon Press.

Gell, A. (1998): Art and agency: An anthropological theory. Oxford, Oxford University Press.
Giddens, A. (1979): Central Problems in Social Theory. Oakland, University of California Press.

Gillespie, S. D. (2001): "Personhood, agency, and mortuary ritual: A case study from the Ancient Maya". Journal of Anthropological Archaeology 20: 73112. https://doi.org/10.1006/jaar.2000.0369

Gimbutas, M. (1974): The Goddesses and Gods of Old Europe. Oakland, University of California Press.

Goldstein, L. G. (1976): Spatial Structure and Social Organization: Regional Manifestations of Mississippian Society. Ph.D. dissertation, Northwestern University.

Goldstein, L. (1981): “One-dimensional archaeology and multi-dimensional people: spatial organization and mortuary analysis", en R. Chapman, I. Kinnes y K. Randsborg (eds.), The Archaeology of Death: 53-69. Cambridge, Cambridge University Press.

Goodenough, W. H. (1965): "Rethinking 'status' and 'role': toward a general model of the cultural organization of social relationships", en M. Banton (ed.), The relevance of models for social anthropology: 1-24. London, Travistoek.

Gosden, C. (1994): Social Being and Time. Oxford, Oxford University Press.

Gosden, C. (1999): Anthropology and Archaeology: A Changing Perspective. London, Routledge.

Gosden, C. (2001): "Making Sense: Archaeology and Aesthetics". World Archaeology 32 (2): 163-167.

Gosden, C. (2004): "Aesthetics, Intelligence and Emotions", en E. DeMarrais, C. Renfrew y C. Gosden (eds.), Rethinking Materiality: 33-40. Cambridge, Cambridge University Press.

Gosden, C. (2005): "What do objects Want?". Journal of Archaeological Method and Theory 12: 193-211. https://doi.org/10.1007/s10816-005-6928-x

Gosden, C. (2008): "Social ontologies". Philosophical Transactions of the Royal Society of London B 363: 2003-2010. DOI: 10.1098/rstb.2008.0013

Gosden, C. y Lock, G. (1998): "Prehistoric histories". World Archaeology 30: 2-12. https://doi.org/10.108 0/00438243.1998.9980393

Gosden, C. y Marshall, Y. (1999): "The Cultural biography of objects". World Archaeology 31 (2): 169-178. https://doi.org/10.1080/00438243.1999.9980439

Gowland, R. (2004): "The Social Identity of Health in Late Roman Britain", en B. Croxford, H. Eckardt, J. Meade y J. Weekes (eds.), TRAC 2003: Proceedings of the Thirteenth Annual Theoretical Roman Archaeology Conference: 135-46. Oxford, Oxbow.

Graham, E. J. (2009): "Becoming persons, becoming ancestors: personhood, memory and the corpse 
in Roman rituals of social remembrance". Archaeological Dialogues 16 (1): 51-74. https://doi. org/10.1017/S1380203809002803

Guerrero, E.; Molist, M.; Kuijt, I. y Anfruns, J. (2009): "Seated Memory: New Insights into Near Eastern Neolithic Mortuary Variability from Tell Halula, Syria”. Current Anthropology 50 (3): 379-391. DOI: $10.1086 / 598211$

Hallam, E. y Hockey, J. L. (2001): Death, Memory and Material Culture. Oxford, Bloomsbury Publishing.

Hamerow, H. (1994): "Migration Theory and the Migration Period", en B. Vyner (ed.), Building on the Past: 164-167. London, Royal Archaeological Institute.

Hamilakis, Y.; Pluciennik, M. y Tarlow, S. (2002): Thinking through the body: archaeologies of corporeality. New York, Springer.

Harland, R. (1987): Superstructuralism: The Philosophy of Structuralism and Post-Structuralism. London, Anybook Ltd.

Harvey, G. (2005): Animism: Respecting the Living World. New York, Columbia University Press.

Hertz, R. (1960) [1907]: Death and the Right Hand. New York, Free Press.

Hill, J. y Gunn, J. (eds.) (1977): The individual in prehistory: studies of variability in style in prehistoric technologies. New York, Academic Press.

Hodder, I. (1982a): Symbols in Action: Ethnoarchaeological Studies of Material Culture. Cambridge, Cambridge University Press.

Hodder, I. (1982b): “Theoretical archaeology: a reactionary view", en I. Hodder (ed.), Symbolic and Structural Archaeology: 1-16. Cambridge, Cambridge University Press.

Hodder, I. (1984): "Burials, houses, women and men in the European Neolithic", en D. Miller y C. Tilley (eds.), Ideology, Power and Prehistory: 51-68. Cambridge, Cambridge University Press.

Hodder, I. (1986): Reading the Past. Current approaches to interpretation in archaeology. Cambridge, Cambridge University Press.

Hodder, I. (1987a): "The contextual analysis of symbolic meanings", en I. Hodder (ed.), The Archaeology of Contextual Meanings: 1-10. Cambridge, Cambridge University Press.

Hodder, I. (1987b): "The Meaning of Discard: Ash and Domestic Space in Baringo", en S. Kent (ed.), Method and Theory for Activity Area Research: An Ethnoarchaeological Approach: 424-448. New York, Columbia University Press.

Hodder, I. (1989): "This is not an article about material culture as text". Journal of Anthropological
Archaeology 8:250-269.https://doi.org/10.1016/02784165(89)90015-9

Hodder, I. (1990): The domestication of Europe: structure and contingence in Neolithic societies. Oxford, Blackwell.

Hodder, I. (1991): "Interpretive archaeology and its role". American Antiquity 56: 7-18. https://doi. org/10.2307/280968

Hofmann, D. y Bickle, P. (2011): “Culture, Tradition and the Settlement Burials of the Linearbandkeramik (LBK) Culture", en B.W. Roberts y M.V. Linden (eds.), Investigating Archaeological Cultures: Material Culture, Variability, and Transmission: 183-201. London, Springer.

Hollimon, S. (1997): "The third gender in native California: Two-spirit undertakers among the Chumash and their neighbors", en C. Claassen y R. A. Joyce (eds.), Women in Prehistory: North America and Mesoamerica: 173-188. Philadelphia, University of Pennsylvania Press.

Hollimon, S. (2006): "The Archaeology of non-binary genders in Native North America", en S. Milledge Nelson (ed.), Handbook of gender in archaeology: 435-450. Lanham, AltaMira Press.

Holtorf, C. (1996): "Towards a Chronology of Megaliths: Understanding Monumental Time and Cultural Memory". Journal of European Archaeology 4: 119152. https://doi.org/10.1179/096576696800688051

Holtorf, C. (1998): "The life-history of megaliths in Mecklenburg-Vorpommern (Germany)". World Archaeology 30: 23-38. https://doi.org/10.1080/00438 243.1998.9980395

Holtorf, C. (2008): "The Past is Now -an Interview with Anders Högberg". European Journal of Archaeology 11 (1): 7-22. https://doi. org/10.1177/1461957108101238

Holtorf, C. y Williams, H. (2006): “Landscapes and memories", en D. Hicks y M. Beaudray (eds.), Cambridge Companion to Historical Archaeology: 235-254. Cambridge, Cambridge University Press.

Homans, G. C. (1941): "Anxiety and ritual: the theories of Malinowski and Radcliffe-Brown". American Anthropologist 43: 164-172. DOI: 10.1525/ aa.1941.43.2.02a00020

Hoskins, J. (1989): “On Losing and Getting a Head: Warfare, Alliance and Exchange in a Changing Sumba 1888-1988". American Ethnologist 16 (3): 419-440. DOI: 10.1525/ae.1989.16.3.02a00010

Hoskins, J. (1998): Biographical Objects: How Things Tell the Stories of People's Lives. London, Routledge. 
Hoskins, M.E. (2005): “Unquiet Graves: Burial Practices of the Roman Corinthians", en N. D. Schowalter y S. J. Friesen (eds.), Urban Religion in Roman Corinth: Interdisciplinary Approaches: 249-280. Cambridge, Cambridge University Press.

Howes, D. (2006): "Scent, sound and synaesthesia: intersensoriality and material culture theory", en C. Tilley, W. Keane, S. Küchler, M. Rowlands y P. Spyer (eds.), Handbook of material culture: 161172. London, Sage.

Hutington, R. y Metcalf, P. (1991): Celebrations of death: the anthropology of mortuary ritual. Cambridge, Cambridge University Press.

Ingold, T. (1993): "The temporality of landscape". World Archaeology 25 (2): 152-174. DOI: 10.1080/00438243.1993.9980235

Ingold, T. (2007): "Materials against materiality". Archaeological Dialogues 14 (1): 1-16. DOI: 10.1017/ S1380203807002127

James, E. O. (1928): "Cremation and the preservation of the dead in North America". American Anthropologist 30: 214-242. DOI: 10.1525/ aa.1928.30.2.02a00030

Jay, M. (2003a): "El ascenso de la hermenéutica y la crisis del ocularcentrismo", en M. Jay, Campos de Fuerza. Entre la historia intelectual y la crítica cultural: 195-220. Buenos Aires, Paidós.

Jay, M. (2003b): "Ideología y ocularcentrismo: ¿hay algo tras el azogue del espejo?", en M. Jay, Campos de Fuerza. Entre la historia intelectual y la crítica cultural: 253-272. Buenos Aires, Paidós.

Johnson, M. (1989): "Conceptions of agency in archaeological interpretation". Journal of Anthropological Archaeology 8: 189-211. https://doi. org/10.1016/0278-4165(89)90024-X

Johnston, S. I. (1999): Restless Dead: Encounters between the Living and the Dead in Ancient Greece. Berkeley, University of California Press.

Jones, A. (2002): “A biography of colour: colour, material histories and personhood in the early Bronze Age of Britain and Ireland", en A. Jones y G. MacGregor (eds.), Colouring the Past: 159-74. Oxford, Oxbow.

Jones, A. (2003): "Technologies of remembrance", en H. Williams (ed.), Archaeologies of remembrance: death and memory in past societies: 65-88. New York, Springer.

Jones, A. (2005a): "Between a rock and a hard place: rock art and mimesis in Neolithic and Bronze Age Scotland", en V. Cummings y A. Pannett (eds.), Set in Stone: New Approaches to Neolithic Monuments in Scotland: 107-117. Oxford, Oxbow.
Jones, A. (2005b): "Matter and memory: colour, remembrance and the Neolithic/Bronze Age transition", en E. DeMarrais, C. Gosden y C. Renfrew, C. (eds.), Rethinking materiality: the engagement of mind with the material world: 167-178. Cambridge, Cambridge University Press.

Jones, A. (2006): “Animated Images: images, agency and landscape in Kilmartin, Argyll, Scotland". Journal of Material Culture 11 (1-2): 211-225. https:// doi.org/10.1177/1359183506063023

Jones, A. (2007): Memory and Material Culture. Cambridge, Cambridge University Press.

Jones, A. (2010): "Burning matters: memory, violence and monumentality in the British Neolithic", en T. Lillios y V. Tsamis (eds.), Material Mnemonics: everyday memory in prehistoric Europe: 85-102. Oxford, Oxbow

Jones, A. y MacGregor, G. (2002): Colouring the past: the significance of colour in archaeological research. Oxford, Oxbow.

Jones. S. (1997): The archaeology of ethnicity: constructing identities in the past and present. London, Routledge.

Joyce, R.A. (2005): "Archaeology of the Body". Annual Review of Anthropology 34: 139-158. https://doi. org/10.1146/annurev.anthro.33.070203.143729

Katz, D. (2007): "Sumerian Funerary Rituals in Context", en N. Laneri (ed.), Performing Death Social Analyses of Funerary: Traditions in the ancient near east and Mediterranean: 167-189. Chicago, University of Chicago.

Kinnes, I. (1975): "Monumental function in British Neolithic burial practices". World Archaeology 7: 16-29. https://doi.org/10.1080/00438243.1975.997 9618

Kirk, T. (2006): "Materiality, personhood and monumentality in Early Neolithic Britain”. Cambridge Archaeological Journal 16 (3): 333-347. https:// doi.org/10.1017/S0959774306000205

Knapp, A. B. y Meskell, L. (1997): "Bodies of evidence in prehistoric Cyprus". Cambridge Archaeological Journal 7 (2): 183-204. https://doi.org/10.1017/ S0959774300001931

Knapp, A. B. y van Dommelen, P. (2008): "Past Practices: Rethinking Individuals and Agents in Archaeology". Cambridge Archaeological Journal 18 (1): 15-34. https://doi.org/10.1017/ S0959774308000024

Knappett, C. (2005): Thinking through material culture: an interdisciplinary perspective. Pennsylvania, Browse Penn Press. 
Knappett, C. y L. Malafouris (eds.) (2008): Material Agency: Towards a Non Anthropocentric Approach. New York, Springer.

Koppytoff, I. (1986): "The cultural biography of things: commoditization perspective", en Appadurai (ed.), The Social Life of Things: Commodities in cultural perspective: 64-91. Cambridge, Cambridge University Press.

Kroeber, A. L. (1927): "Disposal of the dead". American Anthropologist 293: 308-315. DOI: 10.1525/ aa.1927.29.3.02a00090

Küchler, S. y Miller, D. (2005): Clothing as material culture. Oxford, Berg.

Küchler, S. y Were, G. (2005): The art of clothing: a Pacific experience. London, Routledge.

Kuijt, I. (2008): “The Regeneration of Life: Neolithic structures of symbolic remembering and forgetting". Current Anthropology 49(2): 171-197. DOI: $10.1086 / 526097$

Lally, M. y Ardren, T. (2008): "Little Artefacts: Rethinking the constitution of the archaeological infant". Childhood in the Past 1: 62-77. DOI: 10.1179/ cip.2009.1.1.62

Lévi-Strauss, C. (1962): Totemism. London, Merlin Press.

Lewis-Williams, D. y Pearce, D. (2005): Inside the Neolithic Mind. London, Thames \& Hudson.

Lewis-Williams, D. y Dowson, T. (1988): “The signs of all times: entoptic phenomena in Upper Palaeolithic art”. Current Anthropology 29: 201-45.

Lifton, R. J. y Olson, E. (1974): Living and dying. London, Praeger.

Lillios, K. T. (2008): Heraldry for de death: memory, identity and the engraved stone plaques of Neolithic Iberia. Austin, University of Texas Press.

---- (2010): "Mnemonic practices of the Iberian Neolithic: the production and use of the engraved slate plaque-relics", en T. Lillios y V. Tsamis (eds.), $M a-$ terial Mnemonics: everyday memory in prehistoric Europe: 40-72. Oxford, Oxbow.

Lillios, T. y Tsamis, V. (2010): Material mnemonics: everyday memory in prehistoric Europe. Oxford, Oxbow.

Lock, G. (2009): "Human activity in a spatial context", en B. Cunliffe, C. Gosden y R. A. Joyce (eds.), The Oxford Handbook of Archaeology: 169-188. Oxford, Oxford University Press.

Lubbock, J. (1882): The origin of civilization and the primitive condition of man. London, D. Appleton.

Lubbock, J. (1900): Prehistoric times. London, Williams and Norgate.
Lucas, G. (2005): Archaeology of Time. London, Routledge.

Madsen, T. y Jensen, H. J. (1982): "Settlement and land use in early neolithic Denmark". Analecta Praehistorice Liedensia 15: 63-86. http://hdl.handle. net/1887/28082

Matthews, S. G. (2004a): “Gesture, gender, ethnicity: The instantiated communities of Bronze Age Europe". Archaeological Review from Cambridge 19 (2): 56-72.

Matthews, S. G. (2004b): "The Instantiated Identity: Critical Approaches to Studying Gesture and Material Culture", en 'The Materialisation of Social Identities', session at the annual Theoretical Archaeology Group conference, University of Glasgow, Scotland. Diciembre 2004: 17-19.

Mauss, M. (1938): “Une catégorie de l'esprit humain: la notion de personne, celle de 'moi'". Journal of the Royal Anthropological Institute 68: 263-281.

Mauss, M. (1990): The Gift. London, Routledge.

McGuire, R. H. (1982): "The study of ethnicity in historical archaeology". Journal of Anthropological Archaeology 1: 159-178. https://doi. org/10.1016/0278-4165(82)90019-8

McGuire, R. H. (1992): A Marxist Archaeology. Orlando, Academic Press.

Meskell, L. (1998b): "The irresistible body and the seduction of archaeology", en D. Montserrat (ed.), Changing Bodies, Changing Meanings: Studies on the Human Body in Antiquity: 139-161. London, Routledge.

Meskell, L. (1996): "The somatisation of archaeology: Discourses, institutions, corporeality". Norwegian Archaeological Review 29: 1-16. https://doi.org/10. 1080/00293652.1996.9965595

Meskell, L. (2004): Object Worlds in Ancient Egypt: Material Biographies Past and Present. London, Berg.

Meskell, L. (ed.) (2005): Archaeologies of Materiality. Oxford, Blackwell.

Miller, D. (1987): Material Culture and Mass Consumption. Blackwell.

Miller, D. (ed.) (2005): Materiality. London, Duke University Press.

Miller, D. y Tilley, C. (eds.): Ideology, power and prehistory. Cambridge, Cambridge University Press.

Mills, B. J. y Walker, W. H. (eds.) (2008): Memory Work: Archaeologies of Material Practices. Santa Fe, SAR press.

Montelius, G. O. A. (1903): Die Typologische Methode. Stockholm, Almqvist \& Wicksell. 
Moore, H. (1994): A passion for Difference. Cambridge, Cambridge University Press.

Morris, I. (1991): “The archaeology of ancestors: the Saxe/Goldstein hypothesis revisited". Cambridge Archaeological Journal 1(2): 147-169. https://doi. org/10.1017/S0959774300000330

Munn, N. D. (1986): The fame of Gawa. A symbolic study of value transformation in a Massim (Papua New Guniea). London, Duke University Press.

Murphy E. (ed.) (2008): Deviant Burial in the Archaeological record. Oxford, Oxbow.

Nakamura, C. (2005): "Mastering matters: Magical sense and apotropaic figurine worlds of Neo-Assyria”, en L. Meskell (ed.), Archaeologies of materiality: 18-45. Oxford, Blackwell.

Nelson (ed.): Handbook of Gender in Archaeology: 435-450. Lanham, AltaMira Press.

Nilsson Stutz, L. (2003): Embodied Rituals and Ritualized Bodies. Tracing ritual practices in late Mesolithic mortuary practices. Stockholm, Almqvist \& Wiksell International.

Oestigaard, T. (2005): Death and Life-Giving Waters. Cremation, Caste, and Cosmogony in Karmic Traditions. Oxford, Archaeopress.

Olivier, L. (1999): "The Hochdorf "princely" grave and the question of the nature of archaeological funerary assemblages", en T. Murray (ed.), Time and Archaeology: 109-138. London, Routledge.

Olsen, B. (2003): "Material culture after text: remembering things". Norwegian Archaeological Review 36 (3): 87-104. https://doi. org/10.1080/00293650310000650

Olsen, B. (2010): In Defense of things: archaeology and the ontology of objects. Lanham, AltaMira Press.

Oppenheimer, S. (2006): The Origins of the British. London, Robinson Publishing.

Orme, B. (1981): Anthropology for archaeologists. London, Duckworth London.

Osborne, R. y Tanner, J. (2007): Art's Agency and art History. Oxford, Wiley-Blackwell.

O'Shea, J. M. (1984): Mortuary Variability: An Archaeological Investigation. London, Academic Press.

Parker Pearson, M. (1982): "Mortuary practices, society and ideology: ethnoarchaeological study", en I. Hodder (ed.), Symbolic and Structural Archaeology: 99-113. Cambridge, Cambridge University Press

Parker Pearson, M. (1992): “Tombs and monumentality in southern Madagascar: preliminary results of the central Androy survey". Antiquity 66: 941-948. https://doi.org/10.1017/S0003598X00044860

Parker Pearson, M. (1999): The Archaeology of Death and Burial. Stroud, Sutton

Parker Pearson, M. y Ramilisonina, M. (1998): “Stonehenge for the Ancestors: The Stones Pass on the Message". Antiquity 72 (276): 308-326. https://doi. org/10.1017/S0003598X00086592

Peebles, C. y Kus, S. M. (1977): "Some archaeological correlates of ranked societies". American Antiquity 42: 421-448. https://doi. org/10.1177/106939719803200103

Peirce, C.S. (1931-35, 1958): Collected Papers of Charles Sanders Peirce, vols. 1-6. Cambridge, Harvard University Press.

Perry, E. M. y Joyce, R. A. (2001): "Providing a Past for 'Bodies that matter': Judith Butler's Impact on the Archaeology of Gender". International Journal of sexuality and Gender Studies 6 (1-2): 63-75. https://doi.org/10.1023/A:1010142023744

Persson A. W. (1940): New tombs at Dendra. Lund, Harrassowitz.

Piggott, S. (1938): "The Early Bronze Age in Wessex". Proceedings of the Prehistoric Society 4: 52-106. https://doi.org/10.1017/S0079497X00021137

Piggott, S. (1965): Ancient Europe. Edinburgh, Edinburgh University Press.

Pinney, C. (2006): "Four types of visual culture", en C. Tilley, W. Keane, S. Küchler, M. Rowlands y P. Spyer (eds.), Handbook of material culture: 131144. London, Sage.

Preucel, R.W. (2006): Archaeological semiotics. Oxford, Blackwell.

Preucel, R. W. y Bauer, A.A. (2001): “Archaeological pragmatics". Norwegian Archaeological Review 34: 85-96. https://doi.org/10.1080/00293650127469

Proudfoot, E. V. W. (1963): "Report on the excavation of a bell barrow in the parish of Edondsham, Dorset, England, 1959". Proceedings of the Prehistoric Society 29: 395-425. https://doi.org/10.1017/ S0079497X00015450

Raab, L. M. y Goodyear, A. C. (1984): “Middle-Range Theory in Archaeology: A Critical Review of Origins and Applications". American Antiquity 2: 255268. https://doi.org/10.2307/280018

Radcliffe-Brown, A. R. (1922): The Andaman Islanders. Cambridge, Cambridge Universety Press.

Rakita, G.F.M.; Buikstra, J. E.; Beck, L. A. y Williams, S. R. (eds.) (2005): Interacting with the Dead. Perspectives on Mortuary Archaeology for the New Millennium. Florida, University Press of Florida. 
Rebay-Salisbury, K.; Stig, M.L. y Hughes, J. (eds.), Body Parts and Bodies Whole. Changing relations and meanings. Oxford, Oxbow.

Renfrew, A.C. (1973): Before Civilization: The Radiocarbon Revolution and Prehistoric Europe. Londres, Pimlico.

Renfrew, C. (1974): "Space, time and polity", en M. J. Rowlands and J. Friedman (eds.), The Evolution of Social Systems: 89-114. London, University of Pittsburgh Press.

Renfrew, C. (1976): "Megaliths, territories and populations", en S. De Laet (ed.), Acculturation and continuity in Atlantic Europe: 198-220. Brujas, De Tempel.

Reybrouck, D. V. (2000): "Beyond ethnoarchaeology? A critical history on the role of ethnographic analogy in contextual and post-processual archaeology”, en A. Gramsch (ed.), Vergleichen als archäologische Methode-Analogien in den Archäologien: 39-51. Oxford, Archaeopress.

Reynolds, A. (2009): Anglo-Saxon Deviant Burial Customs. Oxford, Oxford University Press.

Richardson, S. (2007): "Death and Dismemberment in Mesopotamia: Discorporation between the Body and Body Politic", en N. Laneri (ed.), Performing Death Social Analyses of Funerary: traditions in the ancient near east and Mediterranean: 189-208. Chicago, Chicago University Press.

Robb, J. (2002): “Time and Biography: Osteobiography of the Italian Neolithic Lifespan", en Y. Hamilakis, M. Pluciennik y S. Tarlow (eds.), Thinking through the Body: 153-172. New York, Springer.

Robb, J. (2007): "Burial treatment as transformations of bodily ideology", en N. Laneri (ed.), Performing Death Social Analyses of Funerary: Traditions in the ancient near east and Mediterranean: 297-288. Chicago, Chicago University Press.

Robb, J. (2010): "Beyond agency". World Archaeology 42 (4): 493-520. https://doi.org/10.1080/00438243. 2010.520856

Robben, A.C.G.M. (ed.) (2004): Death, Mourning, and Burial: A Cross-Cultural Reader. Oxford, WileyBlackwell.

Roberts, B. W. y Linden, M.V. (2011): "Investigating Archaeological Cultures: Material Culture, Variability, and Transmission", en B. W. Roberts y M. V. Linden (eds.), Investigating Archaeological Cultures Material Culture, Variability, and Transmission: 1-22. New York, Springer

Rose, H. J. (1922): "Celestial and terrestrial orientation of the dead". Journal of Royal Anthropological
Institute of Great Britain and Ireland 52: 127-140. DOI: $10.2307 / 2843774$

Rowe, J. H. (1962): "Worsaae's Law and the Use of Grave Lots for Archaeological Dating". American Antiquity 28 (4): 129-137. https://doi. org/10.2307/278369

Rowlands, M. y Tilley, C. (2006): "Monuments and memorials", en C. Tilley, W. Keane, S. Küchler, M. Rowlands y P. Spyer (eds.), Handbook of material culture. London: 500-515.

Saxe, A. (1970): Social dimensions of mortuary practices. Ann Arbor, Univ. Microfilms.

Saxe, A. (1971): "Social dimensions of mortuary practices in a Mesolithic population from Wadi Halfa, Sudan", en J. A. Brown (ed.), Approaches to the social dimensions of mortuary practices: 39-57. Washington, Society for American Archaeology.

Scarre, C. (2000): Monuments and Landscape in Atlantic Europe: Perception and society during the Neolithic and Early Bronze Age. London, Routledge.

Scarre, C. (2004): "Choosing stones, remembering places: geology and intention in the megalithic monuments of Western Europe", en N. Boivin y M-A. Owoc (eds.), Soils, Stones and Symbols. Cultural Perceptions of the Mineral World: 187-202. London, UCL Press.

Scarre, C. (2008): "Shrines of the land and places of power: religion and the transition to farming in Western Europe", en D. S. Whitley y K. W. HaysGilpin (eds.), Belief in the Past. Theoretical approaches to the archaeology of religion: 209-226. California, Left Coast Press.

Scarre, C. (2009): "Stony ground: outcrops, rocks and quarries in the creation of megalithic monuments", en C. Scarre (ed.), Megalithic Quarrying: Sourcing, extracting and manipulating the stones: 3-20. Oxford, British Archaeological Reports.

Sergent, B. (1995): Les Indo-Européens. Histoire, langues, mythes. Paris, Payot.

Service, E. (1962): Primitive social organization. New York, Random House.

Shanks, M. y Tilley, C. (1982): "Ideology, Symbolic Power and Ritual Communication: A Reinterpretation of Neolithic Mortuary Practices", en I. Hodder (ed.), Symbolic and Structural Archaeology: 12954. Cambridge.

Shanks, M. y Tilley, C. (1987a): Re-Constructing Archaeology. Cambridge University Press.

Shanks, M. y Tilley, C. (1987b): Social Theory and Archaeology. Cambridge, Cambirdge University Press. 
Shay, T. (1985): "Differentiated treatment of deviancy at death as revealed in anthropological and archaeological material". Journal of Anthropological Archaeology 4: 221-241. https://doi. org/10.1016/0278-4165(85)90004-2

Shennan, S. (1975): "The social organization at Branc". Antiquity 49: 279-288. https://doi.org/10.1017/ S0003598X00070319

Sørensen, M. L.S. (1991): “Gender construction through appearance", en D. Walde y N. D. Willows (eds.), The Archaeology of Gender: 121-129. Calgary, University of Calgary Archaeological Association.

Sørensen, M. L.S. (1997): "Reading Dress: the construction of social categories and identities in Bronze Age Europe". Journal of European Archaeology 5: 93-114. https://doi. org/10.1179/096576697800703656

Sørensen, M. L.S. (2000): Gender Archaeology. Cambridge, Polity Press.

Spriggs, M. (2008): "Ethnographic parallels and the denial of history". World Archaeology 40 (4): 538552. https://doi.org/10.1080/00438240802453161

Stevens, F. (2007): "Identifying the Body: Representing Self. Art, Ornamentation and the Body in Later Prehistoric Europe”, en J. Sofaer (ed.), Material Identities: 82-98. Oxford, Blackwell.

Sthrathern, M. (1981): "Self-interest and the social good: some implications of Hagen gender Imagery", en S. Orthner y H. Whitehead (eds.), Sexual Meanings: The Cultural Construction of Gender and Sexuality: 166-191. Cambridge, Cambridge University Press.

Sthrathern, M. (1988): The Gender of the Gift: Problems with Women and Problems with Society in Melanesia. Berkeley, University of California Press.

Stringer, M.D. (1999): "Rethinking animism: thoughts from the infancy of our discipline". Journal of the Royal Anthropological Institute 5 (4): 541-555.

Tainer, J. A. (1975): "Social inference and mortuary practices: an experiment in numerical classification". World Archaeology 7 (1): 1-15.

Tainer, J. A. (1977): "Modelling change in prehistoric social systems", en L. Binford (ed.), For Theory Building in Archaeology: Essays on Faunal Remains, Aquatic Resources, Spatial Analysis, and Systemic Modeling. New York: 327-352.

Tainer, J. A. (1978): "Mortuary practices and the study of prehistoric social systems". Archaeological Method and Theory 1: 105-141. https://doi. org/10.1016/B978-0-12-003101-6.50010-X
Tarlow, S. (1999): Bereavement and Commemoration: An Archaeology of Mortality. Oxford, Blackwell.

Tarlow, S. y Nilsson-Stuz, L. (eds.) (2013): The Oxford Handbook of the Archaeology of Dead and Burial. Oxford, Oxford University Press.

Taylor, T. (2002): The Buried Soul: How Humans Invented Death. London, Fourth Estate.

Thomas, J. (1996): Time, Culture and Identity. An Interpretative Archaeology. London, Routledge.

Thomas, J. (1999): Understanding the Neolithic. London, Routledge.

Thomas, J. (2000): "Death, identity and the body in Neolithic Britain". Journal of the Royal Anthropological Institute 6: 603-17. DOI: 10.1111/14679655.00038

Thomas, J. (2002): “Archaeology's humanism and the materiality of the body", en Y. Hamilakis, M. Pluciennik y S. Tarlow (eds.), Thinking Through the Body: Archaeologies of corporeality: 29-46. New York, Springer.

Thomas, J. (2004): Archaeology and Modernity. London, Routledge.

Tilley, C. (1993): "Interpretation and a poetics of the past”, en C. Tilley (ed.), Interpreting Archaeology: 1-27. Oxford, Berg.

Tilley, C. (1994): A Phenomenology of Landscape. Oxford, Berg.

Tilley, C. (1996): "The power of rocks: topography and monument construction on Bodmin Moor". World archaeology 28: 161-176. https://doi.org/10.1080/0 0438243.1996.9980338

Tilley, C. (1999): Metaphor and Material Culture. Oxford, Wiley-Blackwell.

Tilley, C. (2004): The Materiality of Stone: Explorations in Landscape phenomenology. Oxford, Berg.

Tilley, C. (2006): “Objetification”, en C. Tilley, W. Keane, S. Küchler, M. Rowlands y P. Spyer, Handbook of Material Culture: 60-74. Oxford, Sage.

Tilley, C. (2007): "Architectural Order and the Ordening of Imagery in Malta and Ireland: A Comparative perspective", en D. A. Barrowclough y C. Malone (eds.), Cult in Context: reconsidering ritual in archaeology: 118-134. Oxford, Oxbow.

Tilley, C. (2008): Body and image: explorations in landscape phenomenology 2. Oxford, Routledge.

Tilley, C. y W. Bennett (2001): “An archaeology of supernatural places: the case of West Penwith". Journal of the Royal Anthropological Institute 7: 335362. DOI: $10.1111 / 1467-9655.00066$

Treherne, P. (1995): “The Warrior's Beauty: The Masculine Body and Self-Identity in Bronze Age 
Europe". Journal of European Archaeology 3: $105-$ 144. https://doi.org/10.1179/096576695800688269

Turner, T. (1993): “The social skin”, en C. B. Burroughs y J. Ehrenreich (eds.), Reading the social body: 15-39. Iowa, University of Iowa Press

Tyler, J. M. (1921): The new stone age of northern Europe. New York, C. Scribner's sons

Tylor, E. B. (1871): Primitive culture. London, Harper.

Ucko, P.J. (1969): "Ethnography and archaeological interpretation of funerary remains". World Archaeology 1 (2): 262-80. https://doi.org/10.1080/004382 43.1969 .9979444

Van Gennep, A. (2008): Los ritos de paso. Madrid, Alianza Editorial.

Viveiros de Castro, E. (1998): "Cosmological deixis and Amerindian perspectivism". Journal of the Royal Anthropological Institute 4 (3): 469-88. DOI: $10.2307 / 3034157$

Viveiros de Castro, E. (2004): "Perspectivismo y multiculturalismo en la América indígena", en A. Surrallés y P. García Hierro (eds.), Tierra adentro: territorio indígena y percepción del entorno: 37-82. Lima, AIBR.

Wagner, R. (1991): “The fractal person in Big Men and Great Men", en M. Godelier y M. Strathern (eds.), Big Men and Great Men: Personifications of Power in Melanesia: 159-173. Cambridge, Cambridge University Press.

Waterman, S. (1990): "Discourse and Domination: Michel Foucault and the problem of Ideology", en I. Bapty y T. Yates (eds.), Archaeology after structuralism: 79-102. London, Routledge.

Watson, A. (2001): "The sounds of transformation: acoustics, monuments and ritual in the British Neolithic", en N. Price (ed.), The Archaeology of Shamanism: 187-92. London, Routledge.

Watson, A. (2006): "(Un)intentional sound? Acoustics and Neolithic monumenta", en C. Scarre y G. Lawson (eds.), Archaeoacoustics: 11-22. Cambridge, McDonald Institute for Archaeological Research.

Watson, A. y Keating, D. (1999): “Architecture and sound: an acoustic analysis of megalithic monuments in prehistoric Britain”. Antiquity 73: 325336. https://doi.org/10.1017/S0003598X00088281

Watson, A. y Keating, D. (2000): "The architecture of sound in Neolithic Orkney", en A. Ritchie (ed.), Neolithic Orkney in its European Context: 259-263. Cambridge, Cambridge University Press.

Watts, C. (2008): “On Mediation and Material Agency in the Peircean Semiotic", en C. Knappett y L. Malafouris (eds.), Material Agency: Towards a
Non-Anthropocentric Approach: 187-208.New York, Springer.

Watts, C. (ed.) (2013): Relational Archaeologies. Human, animal, things. London, Routledge.

Weiner, A. (1992): Inalienable Possessions: The Paradox of Keeping-while-Giving. Berkeley, University of California Press.

Wells, P. (2008): Image and Response in Early Europe. Bristol, Bristol Classical Press.

Whitley, J. (2002): "Objects with Attitude. Biographical facts and fallacies in the study of late bronze age and early iron age warrior graves". Cambridge Archaeological Journal 12 (2): 217-232. https://doi. org/10.1017/S0959774302000112

Whitley, J. (2002): "Too Many Ancestors". Antiquity 76: 119-126. https://doi.org/10.1017/ S0003598X00089870

Whittle, A. (1997): "Moving on and moving around: Neolithic settlement mobility", en P. Topping (ed.), Neolithic Landscapes: 14-22. Oxford, Oxbow.

Wilder, H. H. y Whipple, R. W. (1917): “The position of the body in aboriginal interments in western Massachusetts". American Anthropologist 19: 372387. doi: 10.1525/aa.1917.19.3.02a00030

Williams, H. (2001): “An Ideology of Transformation: Cremation Rites and Animal Sacrifice in Early Anglo-Saxon England", en N. Price (ed.), The Archaeology of Shamanism: 193-212. London, Routledge.

Williams, H. (ed.) (2003): Archaeologies of remembrance: death and memory in past societies. New York, Springer.

Williams, H. (2006): Death and Memory in Early Medieval Britain. Cambridge, Cambridge University Press.

Williams, H. (2011): "The sense of being seen: ocular effects at Sutton Hoo". Journal of Social Archaeology 11(1): 99-121. https://doi. org/10.1177/1469605310381034

Wilson, P. (1988): The domestication of human species. New Haven, Yale University Press.

Winter, I. J. (2007): “Agency Marked, Agency Ascribed: The Affective Object in Ancient Mesopotamia", en R. Osborne y J. Tanner (eds.), Art's Agency and art History: 42-69. Oxford, Blackwell.

Witmore, C. L. (2006): "Vision, Media, Noise and the Percolation of Time: Symmetrical approaches to the mediation of the material world". Journal of Material Culture 11(3): 267-292. https://doi. org/10.1177/1359183506068806

Wundt, W. (1911): Völkerpsychologie. Leipzig, Leipz Press. 
Yarrow, H. C. (1880): Introduction to the study of mortuary customs among the North American Indians. Washington, Govt. Print. Off.

Yates, T. (1990): "Archaeology through the LookingGlass”, en I. Bapty y T. Yates (eds.), Archaeology after Structuralism: 127-153. London, Routledge.
Yates, T. y Nordbladh, J. (1990): "This Perfect Body, this Virgin text: Between Sex and Gender in Archaeology", en I. Bapty y T. Yates (eds.), Archaeology after Structuralism: 222-239. London, Routledge. 